\title{
An X-ray Photoelectron Spectroscopy Study of Postsynthetic Exchange in UiO-66
}

Jessica C. Moreton, ${ }^{\dagger}$ Jin Xiang Low ${ }^{*}$ Katrina C. Penticoff, ${ }^{+}$Seth M. Cohen ${ }^{\dagger}$ and Lauren Benz ${ }^{*}, *$

${ }^{\dagger}$ Department of Chemistry and Biochemistry, University of California, San Diego, La Jolla, CA 92093, United States

Department of Chemistry and Biochemistry, University of San Diego, San Diego, CA 92110, United States

\section{Supporting Information}

\section{Table of Contents}

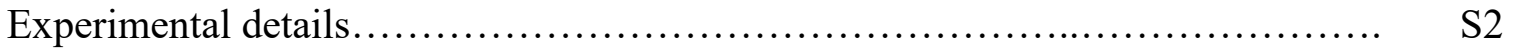

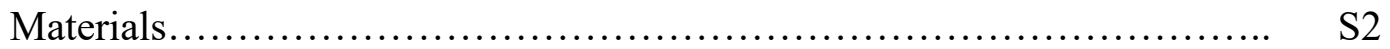

Synthetic procedures................................................ S2

Materials characterization.......................................... S3

Additional experimental results \& discussion.................................. S6

Tables................................................................. S6

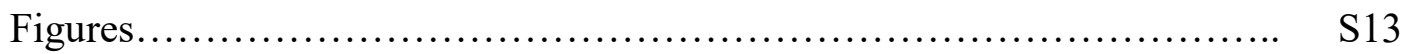

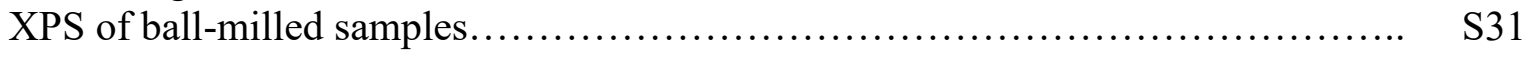

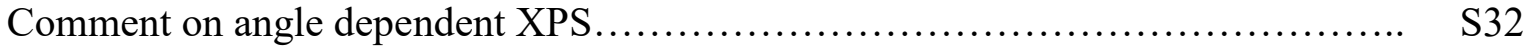

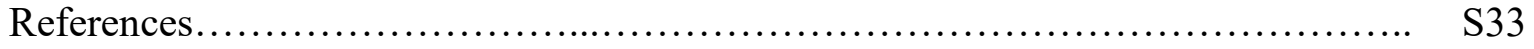




\section{Experimental Details}

$\underline{\text { Materials }}$

All solvents and starting materials were purchased from chemical suppliers and used without further purification with the exception of DMF, which was dried over sieves prior to use. (Sigma Aldrich, Alfa Aesar, EMD, and TCI).

\section{$\underline{\text { Synthetic Procedures }}$}

Deprotection of methyl-protected 2-iodobenzene-1,4-dicarboxylic acid $\mathrm{Me}_{2}$-I-bdc (514 mg, $1.6 \mathrm{mmol}$ ) was dissolved in $9 \mathrm{~mL}$ THF in a $50 \mathrm{~mL}$ round bottom flask. This solution was set stirring and $9 \mathrm{~mL} \mathrm{4 \%}$ aqueous $\mathrm{KOH}$ was added dropwise. This solution was then allowed to stir at room temperature overnight. THF was then removed by rotary evaporation, and the solution was acidified to $\mathrm{pH} 2$ with $\mathrm{HCl}$. The solid product was collected by filtration and dried under vacuum. Yield: $377 \mathrm{mg}$ 2-iodobenzene-1,4-dicarboxylic acid (81\%). ${ }^{1} \mathrm{H}$ NMR (400 MHz, DMSO- $\left.d_{6}\right) \delta 8.14$ (s, 2H). M/z: 291.11, [M-H]- negative ion mode.

Deprotection of methyl-protected 2,5-diiodobenzene-1,4-dicarboxylic acid $\mathrm{Me}_{2}-\mathrm{I}_{2}$-bdc (673 $\mathrm{mg}, 1.5 \mathrm{mmol}$ ) was dissolved in $13 \mathrm{~mL}$ THF in a $50 \mathrm{~mL}$ round bottom flask. This solution was set stirring and $13 \mathrm{~mL} \mathrm{4 \%}$ aqueous $\mathrm{KOH}$ was added dropwise. This solution was then allowed to stir at room temperature overnight. THF was then removed by rotary evaporation, and the solution was acidified to $\mathrm{pH} 2$ with $\mathrm{HCl}$. The solid product was collected by filtration and dried under vacuum. Yield: $520 \mathrm{mg}$ 2,5-diiodobenzene-1,4-dicarboxylic acid (83\%). ${ }^{1} \mathrm{H}$ NMR (400 MHz, DMSO-d $\left.{ }_{6}\right) \delta 8.39(\mathrm{~s}, 1 \mathrm{H}), 7.97(\mathrm{~d}, \mathrm{~J}=7.9 \mathrm{~Hz}, 1 \mathrm{H}), 7.74(\mathrm{~d}, \mathrm{~J}=7.8 \mathrm{~Hz}, 1 \mathrm{H}) . \mathrm{M} / \mathrm{z}: 416.84$, $[\mathrm{M}-\mathrm{H}]^{-}$negative ion mode.

\section{Postsynthetic Exchange of 2,5-diiodobenzene-1,4-dicarboxylic acid into UiO-66 2,5-} diiodobenzene dicarboxylic acid (300 mg, $0.7 \mathrm{mmol}$ ) was dissolved in $6 \mathrm{~mL} \mathrm{4 \%}$ aqueous $\mathrm{KOH}$. This solution was then neutralized to $\mathrm{pH} \sim 7$, and UiO-66 (200 mg, $0.7 \mathrm{mmol}$ linkers, white powder) was added to the vial. The mixture was briefly sonicated to disperse the MOF, then let sit in a $55^{\circ} \mathrm{C}$ oven for 5 days, 1 day, or 1 hour, depending on the experiment. The yellow MOF was collected by centrifugation (fixed-angle rotor, $6000 \mathrm{rpm}, 5 \mathrm{~min}$ ), washed with $3 \times 10 \mathrm{~mL}$ water, then 3x10 mL MeOH. The particles were then soaked in $\mathrm{MeOH}$ for $3 \mathrm{~d}$, with solvent changed daily. The product was then dried under vacuum at room temperature and activated at $105^{\circ} \mathrm{C}$ under vacuum for $12 \mathrm{~h}$. Yield: Generally $150-200 \mathrm{mg}$, or $50-70 \%$.

Synthesis of UiO-66-I Combine $185 \mathrm{mg}(0.79 \mathrm{mmol}) \mathrm{ZrCl}_{4}$ with $230 \mathrm{mg}(0.79 \mathrm{mmol}) 2-$ iodobenzene-1,4-dicarboxylic acid. Dissolve in $45 \mathrm{~mL} \mathrm{DMF}$, then add $1.4 \mathrm{~mL}$ acetic acid and sonicate to disperse/dissolve solids. Portion equally between 3 vials (20ml, PTFE-lined caps) and set heating at $120^{\circ} \mathrm{C}$ for 24 hours. The off-white MOF was collected by centrifugation (fixed-angle rotor, $6000 \mathrm{rpm}, 5 \mathrm{~min}$ ), washed with $3 \times 10 \mathrm{~mL}$ water, then $3 \times 10 \mathrm{~mL} \mathrm{MeOH}$. The particles were then soaked in $\mathrm{MeOH}$ for $3 \mathrm{~d}$, with solvent changed daily. The product was then dried under vacuum at room temperature and activated at $105^{\circ} \mathrm{C}$ under vacuum for $12 \mathrm{~h}$. Yield: $240 \mathrm{mg}$ (76\%). 
Synthesis of UiO-66-I $\mathbf{2}_{\mathbf{2}}$ Combine $191 \mathrm{mg}(0.82 \mathrm{mmol}) \mathrm{ZrCl}_{4}$ with $339 \mathrm{mg}$ 2,5-diiodobenzene1,4-dicarboxylic acid $(0.81 \mathrm{mmol})$. Dissolve in $45 \mathrm{~mL} \mathrm{DMF}$, then add $1.3 \mathrm{~mL}$ acetic acid and sonicate to disperse/dissolve solids. Portion equally between 3 vials ( $20 \mathrm{~mL}$, PTFE-lined caps) and set heating at $120^{\circ} \mathrm{C}$ for 24 hours. The off-white MOF was collected by centrifugation (fixed-angle rotor, $6000 \mathrm{rpm}, 5 \mathrm{~min}$ ), washed with $3 \times 10 \mathrm{~mL}$ water, then $3 \times 10 \mathrm{~mL} \mathrm{MeOH}$. The particles were then soaked in $\mathrm{MeOH}$ for $3 \mathrm{~d}$, with solvent changed daily. The product was then dried under vacuum at room temperature and activated at $105^{\circ} \mathrm{C}$ under vacuum for $12 \mathrm{~h}$. Yield: $182 \mathrm{mg}(42 \%)$.

Mixed-Ligand Synthesis of UiO-66-I Combine $182 \mathrm{mg}(0.78 \mathrm{mmol}) \mathrm{ZrCl}_{4}$ with $72 \mathrm{mg}(0.25$ mmol) I-bdc and $92 \mathrm{mg}(0.55 \mathrm{mmol})$ benzene-1,4-dicarboxylic acid. Dissolve in $45 \mathrm{~mL} \mathrm{DMF}$, then add $1.4 \mathrm{~mL}$ acetic acid and sonicate to disperse/dissolve solids. Portion equally between 3 vials (20 mL, PTFE-lined caps) and set heating at $120^{\circ} \mathrm{C}$ for 24 hours. The off-white MOF was collected by centrifugation (fixed-angle rotor, $6000 \mathrm{rpm}, 5 \mathrm{~min}$ ), washed with $3 \times 10 \mathrm{~mL}$ water, then $3 \times 10 \mathrm{~mL} \mathrm{MeOH}$. The particles were then soaked in $\mathrm{MeOH}$ for $3 \mathrm{~d}$, with solvent changed daily. The product was then dried under vacuum at room temperature and activated at $105^{\circ} \mathrm{C}$ under vacuum for 12h. Yield: $194 \mathrm{mg}(79 \%)$.

Mixed-Ligand Synthesis of UiO-66-I2 Combine $188 \mathrm{mg}(0.81 \mathrm{mmol}) \mathrm{ZrCl}_{4}$ with $98 \mathrm{mg}(0.23$ mmol) 2,5-diiodobenzene-1,4-dicarboxylic acid and $93 \mathrm{mg}(.56 \mathrm{mmol})$ benzene-1,4-dicarboxylic acid. Dissolve in $45 \mathrm{~mL}$ DMF, then add $1.3 \mathrm{~mL}$ acetic acid and sonicate to disperse/dissolve solids. Portion equally between 3 vials ( $20 \mathrm{~mL}$, PTFE-lined caps) and set heating at $120^{\circ} \mathrm{C}$ for 24 hours. The yellow MOF was collected by centrifugation (fixed-angle rotor, $6000 \mathrm{rpm}, 5 \mathrm{~min}$ ), washed with $3 \times 10 \mathrm{~mL}$ water, then $3 \times 10 \mathrm{~mL} \mathrm{MeOH}$. The particles were then soaked in $\mathrm{MeOH}$ for $3 \mathrm{~d}$, with solvent changed daily. The product was then dried under vacuum at room temperature and activated at $105^{\circ} \mathrm{C}$ under vacuum for $12 \mathrm{~h}$. Yield: $270 \mathrm{mg}(95 \%)$.

MOF Digestion $10 \mathrm{mg}$ of MOF were dispersed in $590 \mu \mathrm{L}$ of DMSO-d 6 , then $10 \mu \mathrm{L}$ of $48 \% \mathrm{HF}$ was added. MOF mixtures were sonicated for $30 \mathrm{~min}$ to fully dissolve the MOF for analysis by ${ }^{1} \mathrm{H}$ NMR.

SAFETY NOTE: Concentrated (48\%) HF is extremely hazardous. It causes nerve and bone damage without damaging skin, upon small-area skin contact. Exposure by inhalation, ingestion or large-area skin contact can result in death. Take all recommended safety precautions. All researchers using HF must be properly trained.

\section{Materials Characterization}

ICP, Combustion, and Potentiometric Analysis. Samples were submitted to Galbraith Laboratories, Inc. for bulk elemental analysis and processed according to their internal procedures. Carbon, hydrogen, iodine, and zirconium were analyzed directly, and oxygen was determined by subtraction, using the assumption that no other elements were present.

Iodine: Iodine was analyzed potentiometrically by selective electrode analysis (SEA) following sample preparation G54 Rev 9 and analysis SOP E53-4 Rev10. As per G54 Rev 9, to prepare a sample for iodine analysis, the sample is weighed and either folded into a paper wrapper or 
placed in a gelatin capsule and attached to a platinum wire at the end of a glass rod. A heavywalled Erlenmeyer flask is filled with a quantified volume of absorbing solution and combustion aids as needed, and purged with oxygen at atmospheric pressure. The sample is then ignited and immediately sealed in the flask with a silicone stopper. Once the combustion is complete, the flask is inverted several times to ensure quantitative absorption of the gases produced by the sample. Iodine in its ionic form in aqueous solution can then be determined potentiometrically using an iodide specific electrode (ORION Iodide Electrode, 9453) coupled with a pH meter (Fisher Accumet AR25).

When sample size was sufficient, iodine amount could be determined volumetrically by titration following SOP E35-2. In this procedure, the sample is decomposed in oxygen to form iodate, then treated with excess potassium iodate to produce $I_{2}$, which is then titrated with thiosulfate using starch as an indicator. This procedure was utilized only for the $100 \%$ I-bdc controls.

Zirconium: Zirconium was analyzed via ICP SOP ME-70 following sample preparation G-30B. As per G-30B, to prepare a sample for metal analysis, samples are first charred with sulfuric acid. After charring, the sample is refluxed in nitric acid to solubilize any metals present $(\mathrm{Zr})$. The digested sample is then added to a volumetric flask and diluted prior to analysis. Samples are then analyzed using inductively coupled plasma atomic emission spectrometry (ICP OES Optima). A portion of the solution is converted into aerosol particles using a nebulizer, then transported to a plasma torch. A zirconium emission spectrum is then produced via radiofrequency inductively coupled plasma.

Carbon \& Hydrogen: Carbon and hydrogen were analyzed by combustion analysis SOP ME-14. In this procedure the sample is combusted in pure oxygen at $920-980^{\circ} \mathrm{C}$ to produce $\mathrm{CO}_{2}, \mathrm{H}_{2} \mathrm{O}$, and $\mathrm{N}_{2}$ (PerkinElmer 2400 Series II CHNS/O Analyzer). The PE-2400 separates and analyzes these products in a self-integrating, steady state thermal conductivity analyzer.

SEM MOF samples were placed on conductive carbon tape on a sample holder and coated using a Ir-sputter coating for $7 \mathrm{~s}$. A FEI Quanta 250 scanning electron microscope was used for acquiring images using a $10 \mathrm{kV}$ energy source under vacuum at a working distance of $10 \mathrm{~mm}$.

NMR Proton nuclear magnetic resonance spectra (1H NMR) were recorded on a Varian FTNMR spectrometer $(400 \mathrm{MHz})$. Chemical shifts are quoted in parts per million (ppm) referenced to the appropriate solvent peak or 0 ppm for TMS.

The calculation of $\%$ functionalization by 2-iodobenzene-1,4-dicarboxylic acid of NMR-digested MOFs was performed by integrating representative peaks of bdc and I-bdc at $\sim 8.0 \mathrm{ppm}$ and $\sim 7.75 \mathrm{ppm}$, respectively, then setting the bdc peak area to 4.00 to represent the number of bdc protons present per molecule. The representative peak for I-bdc at $7.75 \mathrm{ppm}$ therefore represents 1 I-bdc proton per molecule of I-bdc, allowing for calculation of the percentage of each component in the NMR digestion liquid, ${ }^{1}$ as shown in the table below.

\begin{tabular}{|c|c|c|c|c|}
\hline $\begin{array}{c}\text { Integration of bdc } \\
\text { peak at } 8.0 \mathrm{ppm}, \\
\text { representing } 4 \\
\text { protons }\end{array}$ & $\begin{array}{c}\text { Integration per } \\
\text { bdc molecule }\end{array}$ & $\begin{array}{c}\text { Integration of I- } \\
\text { bdc peak at 7.75 } \\
\text { ppm, representing } \\
1 \text { proton }\end{array}$ & $\begin{array}{c}\text { Integration } \\
\text { per I-bdc } \\
\text { molecule }\end{array}$ & $\%$ I-bdc \\
\hline Set to 4 & 1 & $\mathrm{x}$ & $\mathrm{x}$ & $\left(\frac{x}{x+1}\right) \times 100 \%$ \\
\hline
\end{tabular}


The calculation of \% functionalization by 2,5-diiodobenzene-1,4-dicarboxylic acid of NMRdigested MOFs was performed by integrating the peaks of bdc and $\mathrm{I}_{2}$-bdc protons at $\sim 8.0 \mathrm{ppm}$ and $\sim 8.15 \mathrm{ppm}$ respectively, then setting the bdc peak area to 4.00 to represent the number of bdc protons present per bdc molecule. The peak for $\mathrm{I}_{2}$-bdc therefore represents 2 protons per $\mathrm{I}_{2}$-bdc molecule, allowing for calculation of the percentage of each component in the NMR digestion liquid, ${ }^{1}$ as shown in the table below.

\begin{tabular}{|c|c|c|c|c|}
\hline $\begin{array}{c}\text { Integration of bdc } \\
\text { peak at 8.0 ppm, } \\
\text { representing 4 } \\
\text { protons }\end{array}$ & $\begin{array}{c}\text { Integration } \\
\text { per bdc } \\
\text { molecule }\end{array}$ & $\begin{array}{c}\text { Integration of } \mathrm{I}_{2}- \\
\text { bdc peak at 8.15 } \\
\text { ppm, representing } \\
2 \text { protons }\end{array}$ & $\begin{array}{c}\text { Integration } \\
\text { per } \mathrm{I}_{2} \text {-bdc } \\
\text { molecule }\end{array}$ & $\% \mathrm{I}_{2}$-bdc \\
\hline Set to 4 & 1 & $\mathrm{x}$ & $\frac{x}{2}$ & $\left(\frac{x / 2}{1+{ }^{x} / 2}\right) \times 100 \%$ \\
\hline
\end{tabular}

Mass Spectrometry Samples were dissolved in methanol at a concentration of $<1 \mathrm{mg} / \mathrm{mL}$ and submitted to the UCSD Molecular Mass Spectrometry Facility (MMSF) for analysis.

$\mathbf{N}_{2}$ Sorption Analysis Approximately $50 \mathrm{mg}$ of MOF powder were placed in a tared sample tube and degassed at $105^{\circ} \mathrm{C}$ on a Micromeritics ASAP 2020 Adsorption Analyzer until the outgas rate was $<5 \mu \mathrm{mHg} / \mathrm{min}$ (12-48 hours). Post-degas, the sample tube was weighed, and then $\mathrm{N}_{2}$ sorption isotherm data were collected at $77 \mathrm{~K}$ using a volumetric technique. BET internal surface areas were then determined from analysis of the Rouquerol plots of the isotherm data, using 4-10 data points each. The guidelines set forth by Rouquerol use four criteria to obtain the most accurate BET surface area values for microporous materials such as MOFs. ${ }^{2}$ Further work by Snurr, ${ }^{3}$ specific to UiO-66, recommends the implementation of criteria I-III for accurate analysis of UiO-66 (since criteria IV is not met in this material). Criteria I, that BET constant C must be positive, and criteria II, that the value $\mathrm{v}(1-\mathrm{p} / \mathrm{p} 0)$ must increase with increasing $\mathrm{p} / \mathrm{p}_{0}$ for all points chosen, are both true for the MOFs in this study. Criteria III states that the total monolayer loading should correspond to a relative pressure within the selected linear region and holds true for our measurements.

Powder X-ray Diffraction PXRD data was collected at room temperature on a Bruker D8 Advance diffractometer, running at $40 \mathrm{Kv}, 4 \mathrm{~mA}$ for $\mathrm{Cu} \mathrm{K \alpha}(\lambda=1.5418 \AA)$, with a scan speed of $0.5 \mathrm{sec} / \mathrm{step}$, a step size of $0.02^{\circ}$ in $2 \Theta$, and a $2 \Theta$ range of $5-50^{\circ}$. Sample holders used were zerobackground Si plates (p-type, B-doped) from MTI Corp. Well-type sample holders $(0.2 \mathrm{~mm}$ depth) were used for powder samples. 


\section{Additional Experimental Results \& Discussion}

\begin{tabular}{|c|c|c|c|c|c|c|c|c|c|c|}
\hline & \multicolumn{3}{|c|}{ I-bdc PSE samples } & \multicolumn{3}{|c|}{ I2-bdc PSE samples } & \multicolumn{4}{|c|}{ Direct synthesis samples } \\
\hline & 1H PSE & 1D PSE & 5D PSE & 1H PSE & 1D PSE & 5D PSE & $100 \%$ I & $30 \% 1$ & $100 \% 12$ & $30 \% 12$ \\
\hline \multicolumn{11}{|l|}{ Surface I:Zr ratios } \\
\hline $\begin{array}{l}\text { XPS-crystalline } \\
\text { (maximum ratios) }\end{array}$ & $\begin{array}{c}0.40 \\
(12 \mathrm{~m})\end{array}$ & $\begin{array}{l}0.40 \\
(2 \mathrm{~m})\end{array}$ & $\begin{array}{c}0.42 \\
(12 \mathrm{~m})\end{array}$ & $\begin{array}{l}0.33 \\
(0 \mathrm{~m})\end{array}$ & $\begin{array}{l}0.75 \\
(2 \mathrm{~m})\end{array}$ & $\begin{array}{c}1.03 \\
(22 \mathrm{~m})\end{array}$ & $\begin{array}{l}0.68 \\
(0 \mathrm{~m})\end{array}$ & $\begin{array}{l}0.28 \\
(2 \mathrm{~m})\end{array}$ & $\begin{array}{l}1.97 \\
(0 \mathrm{~m})\end{array}$ & $\begin{array}{l}0.54 \\
(0 \mathrm{~m})\end{array}$ \\
\hline \multicolumn{11}{|l|}{ Bulk I:Zr ratios } \\
\hline $\begin{array}{l}\text { Elemental } \\
\text { Analyses }\end{array}$ & 0.13 & 0.30 & 0.25 & 0.14 & 0.61 & 0.53 & 0.83 & 0.26 & 1.74 & 0.45 \\
\hline$N M R$ & 0.23 & 0.28 & 0.33 & 0.11 & 0.30 & 0.37 & $\mathrm{~N} / \mathrm{A}$ & 0.33 & $\mathrm{~N} / \mathrm{A}$ & 0.25 \\
\hline $\begin{array}{l}\text { Bulk Averages } \\
\text { (\% change, } \\
\text { surface to bulk) }\end{array}$ & $\begin{array}{c}0.18 \\
(-55 \%) \\
\end{array}$ & $\begin{array}{c}0.29 \\
(-27 \%) \\
\end{array}$ & $\begin{array}{l}0.29 \\
(-31 \%) \\
\end{array}$ & $\begin{array}{c}0.13 \\
(-62 \%) \\
\end{array}$ & $\begin{array}{c}0.46 \\
(-39 \%) \\
\end{array}$ & $\begin{array}{c}0.45 \\
(-56 \%) \\
\end{array}$ & $\begin{array}{c}0.83 \\
(+22 \%) \\
\end{array}$ & $\begin{array}{l}0.30 \\
(+5 \%) \\
\end{array}$ & $\begin{array}{c}1.74 \\
(-12 \%) \\
\end{array}$ & $\begin{array}{c}0.35 \\
(-35 \%) \\
\end{array}$ \\
\hline
\end{tabular}

Table S1. Comparison of surface and bulk I:Zr ratios from several measurements of 1-hour $(1 \mathrm{H})$, 1-day (1D), and 5-day (5D) I-bdc and $\mathrm{I}_{2}$-bdc PSE samples, 100\% I-bdc and 100\% $\mathrm{I}_{2}$-bdc direct synthesis samples, 30\%:70\% mixed linker I-bdc:bdc and 30\%:70\% $\mathrm{I}_{2}$-bdc:bdc synthesis samples. The highest measured surface I:Zr XPS ratios of crystalline nanoparticle samples in a bombardment study are shown in yellow, with corresponding bombardment times given below in parentheses, from the bombardment study discussed in the manuscript and also shown in Table $\mathrm{S} 2$. Bulk averages in orange are from I:Zr ratios measured from several bulk-level measurements including ICP-AES, SEA, titration and NMR.

\section{Discussion of the data in Tables $S 1$ \& $S 2$}

Table $\mathrm{S} 1$ is the source of the data in Figure 1 in the MS. Surface I:Zr ratios given (highlighted in yellow) are the maximum XPS ratios observed with the corresponding bombardment time in parentheses. The first set of bulk data (first row in gray) is from elemental analyses obtained from Galbraith analytical (full data set given below in Table S4, averages given of pre- and post-milled samples when possible as the I:Zr ratio was not observed to change following ball-milling), specifically the I:Zr ratios for all PSE samples and direct synthesis samples listed. The second set of bulk data (second row in gray) is from NMR digestion of the samples (data shown in Figures S10, S11, S15, S19 \& S23). The average of these two values is given in orange, with the percentage change of the bulk ratio compared to the surface shown in parentheses. While the discussion in the manuscript focuses on the comparison of the surface and bulk data of the PSE samples, additional discussion of the control data is provided here.

When comparing the maximum surface I:Zr XPS ratio to the bulk ratio in the $100 \%$ I-bdc sample in Table S1, the surface I:Zr ratio appears to be less than the bulk ratio $(0.68 \pm 0.07$ surface vs. $0.83 \pm 0.11$ bulk), opposing the trend observed for the I-bdc PSE samples, however, the values overlap slightly when considering the error bars. In general, a decrease in the $\mathrm{I}: \mathrm{Zr}$ 
ratio when comparing surface to bulk may be attributed to the existence of a layer of physisorbed and/or chemically bound non-native surface groups, as such a layer has been reported for other MOFs. ${ }^{4,5}$ For example, in an earlier study of ZIF-8, we found XPS evidence for a metal-rich surface terminated by carbonate and water or hydroxyl groups, ${ }^{5}$ and computational evidence suggests these groups form by reaction with species present in air. ${ }^{6}$ Digestion for bulk analysis thus may reveal a more iodine-rich interior, particularly for samples with high bulk iodine content. The $30 \%$-I-bdc: $70 \%$ bdc sample had similar bulk and surface ratios $(0.28 \pm 0.03$ surface vs. $0.29 \pm 0.05$ bulk). A surface layer is likely also present on the PSE samples, however, argon bombardment intended to remove this layer revealed the presence of a higher iodine ratio. Likewise, the $100 \% \mathrm{I}_{2}$-bdc control sample surface and bulk measurements agree within error $(1.97 \pm 0.22$ surface vs. $1.74 \pm 0.22$ bulk) though looking at only the average values the surface value is larger. The same is true of the $30 \% \mathrm{I}_{2}$-bdc: $70 \%$ bdc sample $(0.54 \pm 0.06$ surface vs. 0.35 \pm 0.14 bulk).

Interestingly, bombardment of the $100 \%$ control sample (Table S2) did not change the $\mathrm{I}: Z r$ ratio within a 12-minute time frame, however, the competing effects of non-native overlayer (Zn-rich) removal, and more rapid iodine removal with bombardment may be in balance. In contrast, the $100 \% \mathrm{I}_{2}$-bdc control sample I:Zr ratio dropped with bombardment time (Table S2), and we attribute this to a difference in the general quality and amorphous nature of the $\mathrm{I}_{2}$-bdc samples.

As discussed in the manuscript, the quality of the $\mathrm{I}_{2}$-bdc samples was generally worse than that of the I-bdc samples, particularly for the direct synthesis $100 \%$ and $30 \% \mathrm{I}_{2}$-bdc samples. The SEM images S6 and S9 show less crystalline-looking particles for both of these direct synthesis samples in comparison to unmodified UiO-66 (ie. Figure S14) and the 100\% and $30 \%$ I-bdc direct synthesis samples. The 100\% and 30\% $\mathrm{I}_{2}$-bdc samples also exhibit the lowest BET surface areas, at $260 \mathrm{~m}^{2} / \mathrm{g}$ and $690 \mathrm{~m}^{2} / \mathrm{g}$, respectively, compared to $1300 \mathrm{~m}^{2} / \mathrm{g}$ obtained for unmodified UiO-66. The 100\% I-bdc and 30\% I-bdc direct synthesis samples also exhibited higher BET $\mathrm{N}_{2}$ uptake values compared to the $\mathrm{I}_{2}$-bdc samples, at $690 \mathrm{~m}^{2} / \mathrm{g}$ and $1130 \mathrm{~m}^{2} / \mathrm{g}$, respectively. Furthermore, the $100 \% \mathrm{I}_{2}$-bdc sample shows evidence of amorphous character by PXRD (Figure S4). 


\begin{tabular}{|c|c|c|c|c|c|c|}
\hline \multirow[t]{2}{*}{$\begin{array}{l}\text { Preparation } \\
\text { conditions }\end{array}$} & \multicolumn{3}{|c|}{$\begin{array}{c}\text { I-bdc samples } \\
\text { Argon bombardment time }\end{array}$} & \multicolumn{3}{|c|}{$\begin{array}{c}\mathrm{I}_{2} \text {-bdc samples } \\
\text { Argon bombardment time }\end{array}$} \\
\hline & $0 \mathrm{~min}$ & $2 \mathrm{~min}$ & $12 \mathrm{~min}$ & $0 \mathrm{~min}$ & $2 \mathrm{~min}$ & $12 \mathrm{~min}$ \\
\hline $100 \%$, crystalline & 0.68 & 0.68 & 0.67 & 1.97 & 1.52 & 1.32 \\
\hline $30 \%$, crystalline & 0.23 & 0.28 & 0.27 & 0.54 & 0.46 & 0.36 \\
\hline 1-hourPSE, crystalline & 0.14 & 0.36 & $0.40^{*}$ & $0.33^{*}$ & 0.30 & 0.31 \\
\hline 1-day PSE, crystalline & 0.30 & $0.40^{*}$ & 0.39 & 0.36 & $0.75^{*}$ & 0.61 \\
\hline 5-day PSE, crystalline & 0.27 & 0.40 & $0.42^{*}$ & 0.57 & $0.68^{*}$ & 0.53 \\
\hline & $0 \mathrm{~min}$ & $2 \mathrm{~min}$ & $12 \mathrm{~min}$ & $0 \mathrm{~min}$ & $2 \mathrm{~min}$ & $12 \mathrm{~min}$ \\
\hline $100 \%$, amorphized & 1.20 & 0.77 & 0.50 & 1.58 & 0.98 & 0.61 \\
\hline 30\%, amorphized & 0.26 & 0.23 & 0.19 & 0.25 & 0.32 & 0.33 \\
\hline 1-hour PSE, amorphized & $0.14^{*}$ & 0.14 & 0.12 & $0.20^{*}$ & 0.18 & 0.11 \\
\hline 1-day PSE, amorphized & 0.29 & $0.30^{*}$ & 0.25 & $0.77^{*}$ & 0.55 & 0.33 \\
\hline 5-day PSE, amorphized & $0.42^{*}$ & 0.37 & 0.30 & $1.21^{*}$ & 1.08 & 0.81 \\
\hline
\end{tabular}

Table S2. Iodine to zirconium ratios for I-bdc and $\mathrm{I}_{2}$-bdc UiO-66 samples pre and post ballmilling (crystalline and amorphous, respectively). 100\% I-bdc/I $\mathrm{I}_{2}-\mathrm{bdc}$ direct synthesis, 30\% I$\mathrm{bdc} / \mathrm{I}_{2}-\mathrm{bdc}$ direct synthesis, and PSE samples of I-bdc/I - -bdc for varying exchange times: $5 \mathrm{~d}, 1 \mathrm{~d}$, and $1 \mathrm{~h}$. *Largest observed ratio over the bombardment time frame shown. Average ratios are reported for the $100 \% \mathrm{I}$-bdc, crystalline control sample, as well as the 1-hour $\mathrm{I}_{2}$-bdc crystalline PSE sample, which were run in triplicate to determine an average RSD of $11 \%$ for the I:Zr XPS ratios. 


\begin{tabular}{|c|c|c|c|c|c|c|c|c|c|c|}
\hline \multicolumn{11}{|c|}{ I-bdc samples, XPS area analysis } \\
\hline $\begin{array}{l}\text { Elemental } \\
\text { Region }\end{array}$ & \multicolumn{3}{|c|}{ Oxygen $1 s$} & \multicolumn{3}{|l|}{ Carbon $1 s$} & \multicolumn{3}{|l|}{ Iodine $3 d$} & \multirow{2}{*}{$\begin{array}{l}\text { Zirconium } \\
3 d^{*} \\
0 \text { to } 12\end{array}$} \\
\hline $\begin{array}{l}\text { Bombardment } \\
\text { time, min }\end{array}$ & 0 & 2 & 12 & 0 & 2 & 12 & 0 & 2 & 12 & \\
\hline \multicolumn{11}{|l|}{ Sample: } \\
\hline $100 \%(\mathrm{RSD}) * *$ & $6.93(2)$ & $4.31(16)$ & $3.28(33)$ & $14.52(14)$ & $9.85(13)$ & $7.56(18)$ & $0.68(5)$ & $0.68(12)$ & $0.67(9)$ & 1 \\
\hline $\begin{array}{l}100 \% \text {, ball- } \\
\text { milled }\end{array}$ & 6.19 & 4.13 & 2.30 & 24.38 & 14.38 & 5.33 & 1.20 & 0.77 & 0.50 & 1 \\
\hline $30 \%$ & 5.67 & 3.79 & 3.61 & 11.86 & 9.84 & 8.71 & 0.23 & 0.28 & 0.27 & 1 \\
\hline $\begin{array}{l}30 \% \text {, ball- } \\
\text { milled }\end{array}$ & 5.61 & 4.23 & 3.87 & 12.15 & 9.56 & 7.59 & 0.26 & 0.23 & 0.19 & 1 \\
\hline 5 day PSE & 4.99 & 3.33 & 2.49 & 9.00 & 7.02 & 4.69 & 0.27 & 0.40 & 0.42 & 1 \\
\hline $\begin{array}{l}5 \text { day PSE, } \\
\text { ball-milled }\end{array}$ & 7.20 & 4.92 & 3.02 & 15.42 & 11.82 & 8.20 & 0.42 & 0.37 & 0.30 & 1 \\
\hline 1 day PSE & 5.74 & 4.22 & 3.08 & 13.54 & 10.45 & 9.63 & 0.30 & 0.40 & 0.39 & 1 \\
\hline $\begin{array}{l}1 \text { day PSE, } \\
\text { ball-milled }\end{array}$ & 6.49 & 4.62 & 2.72 & 12.05 & 10.87 & 4.93 & 0.29 & 0.30 & 0.25 & 1 \\
\hline 1 hour PSE & 5.28 & 3.87 & 2.96 & 10.63 & 5.51 & 6.81 & 0.14 & 0.36 & 0.40 & 1 \\
\hline $\begin{array}{l}1 \text { hour PSE, } \\
\text { ball-milled }\end{array}$ & 5.44 & 4.52 & 3.08 & 11.95 & 11.14 & 8.55 & 0.14 & 0.14 & 0.12 & 1 \\
\hline \multicolumn{11}{|c|}{${ }^{*}$ All areas normalized to the zirconium $3 d$ region ${ }^{* *}$ Average of 3 samples with relative standard deviations } \\
\hline \multicolumn{11}{|c|}{ I2-bdc samples, XPS area analysis } \\
\hline $\begin{array}{l}\text { Elemental } \\
\text { Region }\end{array}$ & \multicolumn{3}{|c|}{ Oxygen $1 s$} & \multicolumn{3}{|l|}{ Carbon 1 s } & \multicolumn{3}{|l|}{ Iodine $3 d$} & $\begin{array}{l}\text { Zirconium } \\
3 d^{*}\end{array}$ \\
\hline $\begin{array}{l}\text { Bombardment } \\
\text { time, min }\end{array}$ & 0 & 2 & 12 & 0 & 2 & 12 & 0 & 2 & 12 & 0 to 12 \\
\hline Sample: & & & & & & & & & & 1 \\
\hline $100 \%$ & 6.53 & 3.67 & 3.12 & 19.15 & 11.32 & 7.43 & 1.97 & 1.52 & 1.32 & 1 \\
\hline $\begin{array}{l}100 \% \text {, ball- } \\
\text { milled }\end{array}$ & 5.96 & 2.80 & 2.33 & 13.69 & 8.25 & 4.34 & 1.58 & 0.98 & 0.61 & 1 \\
\hline $30 \%$ & 6.37 & 3.87 & 3.35 & 13.76 & 10.61 & 10.49 & 0.54 & 0.46 & 0.36 & 1 \\
\hline $\begin{array}{l}30 \% \text {, ball- } \\
\text { milled }\end{array}$ & 4.32 & 3.41 & 3.24 & 7.42 & 5.41 & 4.58 & 0.25 & 0.32 & 0.33 & 1 \\
\hline 5 day PSE & 5.91 & 3.65 & 2.52 & 16.11 & 13.15 & 10.17 & 0.57 & 0.68 & 0.53 & 1 \\
\hline $\begin{array}{l}5 \text { day PSE, } \\
\text { ball-milled }\end{array}$ & 6.55 & 3.96 & 5.11 & 18.40 & 14.72 & 18.90 & 1.21 & 1.08 & 0.81 & 1 \\
\hline 1 day PSE & 5.31 & 5.38 & 3.46 & 12.99 & 13.96 & 10.81 & 0.36 & 0.75 & 0.61 & 1 \\
\hline $\begin{array}{l}1 \text { day PSE, } \\
\text { ball-milled }\end{array}$ & 6.07 & 3.12 & 2.32 & 12.34 & 8.46 & 5.98 & 0.77 & 0.55 & 0.33 & 1 \\
\hline $\begin{array}{l}1 \text { hour PSE, } \\
\text { AVE (RSD)** }\end{array}$ & $5.81(24)$ & $3.89(37)$ & $3.04(20)$ & $13.57(9)$ & $14.17(51)$ & $8.73(49)$ & $0.33(12)$ & $0.30(17)$ & $0.31(13)$ & 1 \\
\hline $\begin{array}{l}1 \text { hour PSE, } \\
\text { ball-milled }\end{array}$ & 5.41 & 3.41 & 2.08 & 14.46 & 13.01 & 7.02 & 0.20 & 0.18 & 0.11 & 1 \\
\hline
\end{tabular}

Table S3. XPS elemental ratios of all regions scanned, normalized to the $\mathrm{Zr} 3 \mathrm{~d}$ region. Note that tables S1 and S2 are summary tables which focus on the iodine:zirconium ratio, while all elements scanned are given here, including $\mathrm{O}, \mathrm{C}$, I and Zr. 
2-Iodobenzene-1,4-dicarboxylate (I-bdc) PSE UiO-66 samples:

\begin{tabular}{|c|c|c|c|c|c|c|c|c|}
\hline \multicolumn{4}{|c|}{1 hour PSE, I-bdc, pre ball-milling } & \multicolumn{5}{|c|}{1 hour PSE, I-bdc, post ball-milling } \\
\hline Element & $\%$ mass & moles & $\begin{array}{c}\text { Ratio, } \\
\text { normalized } \\
\text { to } \mathrm{Zr}\end{array}$ & $\begin{array}{c}\% \\
\text { mass }\end{array}$ & moles & $\begin{array}{l}\text { Ratio, } \\
\text { normalize } \\
\text { d to } \mathrm{Zr}\end{array}$ & $\begin{array}{c}\text { Averag } \\
\text { e } \\
\text { ratio }\end{array}$ & $\begin{array}{l}\text { Relative } \\
\text { standard } \\
\text { deviation }\end{array}$ \\
\hline $\mathrm{C}$ & 25.56 & 2.13 & 7.41 & 28.49 & 2.37 & 8.17 & 7.79 & 6.86 \\
\hline $\mathrm{H}$ & 3.20 & 3.17 & 11.05 & 2.44 & 2.42 & 8.33 & 9.69 & 19.85 \\
\hline $\mathrm{I}$ & 4.06 & 0.03 & 0.11 & 5.40 & 0.04 & 0.15 & 0.13 & 19.24 \\
\hline $\mathrm{Zr}$ & 26.20 & 0.29 & 1.00 & 26.50 & 0.29 & 1.00 & N/A & $\mathrm{N} / \mathrm{A}$ \\
\hline $\mathrm{O}$ & 40.98 & 2.56 & 8.92 & 37.17 & 2.32 & 8.00 & 8.46 & 7.70 \\
\hline \multicolumn{4}{|c|}{1 day PSE, I-bdc, pre ball-milling } & \multicolumn{5}{|c|}{1 day PSE, I-bdc, post ball-milling } \\
\hline Element & \% mass & moles & $\begin{array}{c}\text { Ratio, } \\
\text { normalized } \\
\text { to } \mathrm{Zr}\end{array}$ & $\begin{array}{c}\% \\
\text { mass }\end{array}$ & moles & $\begin{array}{c}\text { Ratio, } \\
\text { normalize } \\
\text { d to } \mathrm{Zr}\end{array}$ & $\begin{array}{l}\text { Averag } \\
\text { e } \\
\text { ratio }\end{array}$ & $\begin{array}{l}\text { Relative } \\
\text { standard } \\
\text { deviation }\end{array}$ \\
\hline $\mathrm{C}$ & 22.90 & 1.91 & 8.17 & 26.72 & 2.22 & 8.32 & 8.24 & 1.30 \\
\hline $\mathrm{H}$ & 3.57 & 3.54 & 15.17 & 2.22 & 2.20 & 8.23 & 11.70 & 41.90 \\
\hline $\mathrm{I}$ & 8.83 & 0.07 & 0.30 & 10.53 & 0.08 & 0.31 & 0.30 & 2.84 \\
\hline $\mathrm{Zr}$ & 21.30 & 0.23 & 1.00 & 24.40 & 0.27 & 1.00 & $\mathrm{~N} / \mathrm{A}$ & $\mathrm{N} / \mathrm{A}$ \\
\hline $\mathrm{O}$ & 43.40 & 2.71 & 11.62 & 36.13 & 2.26 & 8.44 & 10.03 & 22.38 \\
\hline \multicolumn{4}{|c|}{5 day PSE, I-bdc, pre ball-milling* } & \multicolumn{5}{|c|}{5 day PSE, I-bdc, post ball-milling } \\
\hline Element & $\%$ mass & moles & $\begin{array}{c}\text { Ratio, } \\
\text { normalized } \\
\text { to } \mathrm{Zr} \\
\end{array}$ & $\begin{array}{c}\% \\
\text { mass } \\
\end{array}$ & moles & $\begin{array}{c}\text { Ratio, } \\
\text { normalize } \\
\text { d to } \mathrm{Zr}\end{array}$ & $\begin{array}{l}\text { Averag } \\
\text { e } \\
\text { ratio } \\
\end{array}$ & $\begin{array}{l}\text { Relative } \\
\text { standard } \\
\text { deviation }\end{array}$ \\
\hline I & -- & -- & -- & 9.51 & 0.07 & 0.25 & -- & -- \\
\hline $\mathrm{Zr}$ & -- & -- & -- & 27.30 & 0.30 & 1.00 & -- & -- \\
\hline
\end{tabular}

*Sample not run, I:Zr ratios pre- and post-milling presumed to be the same

\section{2,5-Diiodobenzene-1,4-dicarboxylate (I2-bdc) PSE UiO-66 samples:}

\begin{tabular}{|c|c|c|c|c|c|c|c|c|}
\hline \multicolumn{4}{|c|}{1 hour PSE, $\mathbf{I}_{2}$-bdc, pre ball-milling } & \multicolumn{5}{|c|}{1 hour PSE, $\mathbf{I}_{2}$-bdc, post ball-milling } \\
\hline Element & $\%$ mass & moles & $\begin{array}{r}\text { Ratio, } \\
\text { normalized } \\
\text { to } \mathrm{Zr}\end{array}$ & $\begin{array}{r}\% \\
\text { mass }\end{array}$ & moles & $\begin{array}{r}\text { Ratio, } \\
\text { normalized } \\
\text { to } \mathrm{Zr}\end{array}$ & $\begin{array}{l}\text { Averag } \\
\text { e } \\
\quad \text { ratio }\end{array}$ & $\begin{array}{r}\text { Relative } \\
\text { standard } \\
\text { deviatio }\end{array}$ \\
\hline $\mathrm{C}$ & 27.18 & 2.26 & 8.22 & 28.54 & 2.38 & 8.15 & 8.19 & 0.65 \\
\hline $\mathrm{H}$ & 2.50 & 2.48 & 9.01 & 2.02 & 2.00 & 6.87 & 7.94 & 19.06 \\
\hline $\mathrm{I}$ & 4.05 & 0.03 & 0.12 & 6.16 & 0.05 & 0.17 & 0.14 & 25.27 \\
\hline $\mathrm{Zr}$ & 25.10 & 0.28 & 1.00 & 26.60 & 0.29 & 1.00 & $\mathrm{~N} / \mathrm{A}$ & $\mathrm{N} / \mathrm{A}$ \\
\hline $\mathrm{O}$ & 41.17 & 2.57 & 9.35 & 36.68 & 2.29 & 7.86 & 8.61 & 12.24 \\
\hline \multicolumn{4}{|c|}{1 day PSE, $\mathbf{I}_{2}$-bdc, pre ball-milling } & \multicolumn{5}{|c|}{1 day PSE, $I_{2}$-bdc, post ball-milling } \\
\hline Element & $\%$ mass & moles & $\begin{array}{l}\text { Ratio, } \\
\text { normalized } \\
\text { to } \mathrm{Zr}\end{array}$ & $\begin{array}{c}\% \\
\text { mass }\end{array}$ & moles & $\begin{array}{l}\text { Ratio, } \\
\text { normalized } \\
\text { to } \mathrm{Zr}\end{array}$ & $\begin{array}{l}\text { Averag } \\
\text { e } \\
\text { ratio }\end{array}$ & $\begin{array}{c}\text { Relative } \\
\text { standard } \\
\text { deviatio } \\
n\end{array}$ \\
\hline $\bar{C}$ & 21.41 & 1.78 & 7.78 & 24.06 & 2.00 & 8.42 & 8.10 & 5.59 \\
\hline $\mathrm{H}$ & 2.82 & 2.80 & 12.21 & 1.75 & 1.74 & 7.30 & 9.76 & 35.61 \\
\hline $\mathrm{I}$ & 16.97 & 0.13 & 0.58 & 19.09 & 0.15 & 0.63 & 0.61 & 5.66 \\
\hline $\mathrm{Zr}$ & 20.90 & 0.23 & 1.00 & 21.70 & 0.24 & 1.00 & N/A & $\mathrm{N} / \mathrm{A}$ \\
\hline $\mathrm{O}$ & 37.90 & 2.37 & 10.34 & 33.40 & 2.09 & 8.78 & 9.56 & 11.57 \\
\hline
\end{tabular}


5 day PSE, $\mathbf{I}_{2}$-bdc, pre ball-milling

\begin{tabular}{|l|c|c|c|}
\hline Element & \% mass & moles & $\begin{array}{c}\text { Ratio, } \\
\text { normalized } \\
\text { to } \mathbf{Z r}\end{array}$ \\
\hline $\mathrm{I}$ & 16.38 & 0.13 & 0.53 \\
\hline $\mathrm{Zr}$ & 22.20 & 0.24 & 1.00 \\
\hline
\end{tabular}

*Sample not run, I:Zr ratios pre- and post-milling presumed to be the same
5 day PSE, $\mathbf{I}_{2}$-bdc, post ball-milling*

\begin{tabular}{|c|c|c|c|c|}
$\begin{array}{c}\% \\
\text { mass }\end{array}$ & moles & $\begin{array}{c}\text { Ratio, } \\
\text { normalized } \\
\text { to Zr }\end{array}$ & $\begin{array}{l}\text { Averag } \\
\text { e } \\
\text { ratio }\end{array}$ & $\begin{array}{c}\text { Relative } \\
\text { standard } \\
\text { deviatio } \\
\text { n }\end{array}$ \\
\hline-- & -- & -- & -- & -- \\
\hline-- & -- & -- & -- & -- \\
\hline
\end{tabular}

Control \& Direct Synthesis Samples:

\begin{tabular}{|c|c|c|c|c|c|c|c|c|}
\hline \multicolumn{4}{|c|}{ UiO-66 control, pre-milling } & \multicolumn{5}{|c|}{ UiO-66 control, post-milling } \\
\hline Element & $\begin{array}{c}\% \\
\text { mass }\end{array}$ & moles & $\begin{array}{c}\text { Ratio, } \\
\text { normalized } \\
\text { to } \mathrm{Zr}\end{array}$ & $\%$ mass & moles & $\begin{array}{l}\text { Ratio, } \\
\text { normalized } \\
\text { to } \mathrm{Zr}\end{array}$ & $\begin{array}{c}\text { Average } \\
\text { ratio }\end{array}$ & $\begin{array}{l}\text { Standard } \\
\text { Deviation }\end{array}$ \\
\hline $\mathrm{C}$ & 26.13 & 2.18 & 7.84 & 29.98 & 2.50 & 8.63 & 8.23 & 6.70 \\
\hline $\mathrm{H}$ & 3.40 & 3.37 & 12.16 & 2.55 & 2.53 & 8.74 & 10.45 & 23.14 \\
\hline $\mathrm{I}$ & 0.03 & 0.00 & 0.00 & 0.27 & 0.00 & 0.01 & 0.00 & $\mathrm{~N} / \mathrm{A}$ \\
\hline $\mathrm{Zr}$ & 25.30 & 0.28 & 1.00 & 26.40 & 0.29 & 1.00 & $\mathrm{~N} / \mathrm{A}$ & $\mathrm{N} / \mathrm{A}$ \\
\hline $\mathrm{O}$ & 45.14 & 2.82 & 10.17 & 40.80 & 2.55 & 8.81 & 9.49 & 10.14 \\
\hline \multicolumn{4}{|c|}{$100 \%$ I-bdc direct, pre ball-milling } & \multicolumn{5}{|c|}{$100 \%$ I-bdc direct, post ball-milling } \\
\hline Element & $\begin{array}{c}\% \\
\text { mass }\end{array}$ & moles & $\begin{array}{c}\text { Ratio, } \\
\text { normalized } \\
\text { to } \mathrm{Zr}\end{array}$ & \% mass & moles & $\begin{array}{c}\text { Ratio, } \\
\text { normalized } \\
\text { to } \mathrm{Zr}\end{array}$ & $\begin{array}{c}\text { Average } \\
\text { ratio }\end{array}$ & $\begin{array}{l}\text { Standard } \\
\text { Deviation }\end{array}$ \\
\hline $\mathrm{C}$ & 22.22 & 1.85 & 7.57 & 21.94 & 1.83 & 7.71 & 7.64 & 1.36 \\
\hline $\mathrm{H}$ & 1.50 & 1.49 & 6.09 & 1.53 & 1.52 & 6.41 & 6.25 & 3.65 \\
\hline $\mathrm{I}$ & 25.07 & 0.20 & 0.81 & 25.61 & 0.20 & 0.85 & 0.83 & 3.76 \\
\hline $\mathrm{Zr}$ & 22.30 & 0.24 & 1.00 & 21.60 & 0.24 & 1.00 & N/A & N/A \\
\hline $\mathrm{O}$ & 28.91 & 1.81 & 7.39 & 29.32 & 1.83 & 7.74 & 7.57 & 3.25 \\
\hline \multicolumn{4}{|c|}{$\mathbf{3 0} \%$ I-bdc direct, pre ball-milling } & \multicolumn{5}{|c|}{ 30\% I-bdc direct, post ball-milling* } \\
\hline Element & $\begin{array}{c}\% \\
\text { mass }\end{array}$ & moles & $\begin{array}{c}\text { Ratio, } \\
\text { normalized } \\
\text { to } \mathrm{Zr}\end{array}$ & \% mass & moles & $\begin{array}{c}\text { Ratio, } \\
\text { normalized } \\
\text { to } \mathrm{Zr} \\
\end{array}$ & $\begin{array}{c}\text { Average } \\
\text { ratio }\end{array}$ & $\begin{array}{l}\text { Standard } \\
\text { Deviation }\end{array}$ \\
\hline $\mathrm{C}$ & 29.74 & 2.48 & 8.34 & -- & -- & -- & -- & -- \\
\hline $\mathrm{H}$ & 1.60 & 1.59 & 5.34 & -- & -- & -- & -- & -- \\
\hline I & 9.63 & 0.08 & 0.26 & -- & -- & -- & -- & -- \\
\hline $\mathrm{Zr}$ & 27.10 & 0.30 & 1.00 & -- & -- & -- & -- & -- \\
\hline $\mathrm{O}$ & 31.93 & 2.00 & 6.72 & -- & -- & -- & -- & -- \\
\hline \multicolumn{4}{|c|}{$100 \% \mathrm{I}_{2}$-bdc direct, pre ball-milling } & \multicolumn{5}{|c|}{$100 \% I_{2}$-bdc direct, post ball-milling* } \\
\hline Element & $\begin{array}{c}\% \\
\text { mass }\end{array}$ & moles & $\begin{array}{c}\text { Ratio, } \\
\text { normalized } \\
\text { to } \mathrm{Zr}\end{array}$ & $\%$ mass & moles & $\begin{array}{c}\text { Ratio, } \\
\text { normalized } \\
\text { to } \mathrm{Zr}\end{array}$ & $\begin{array}{c}\text { Average } \\
\text { ratio }\end{array}$ & $\begin{array}{l}\text { Standard } \\
\text { Deviation }\end{array}$ \\
\hline $\mathrm{C}$ & 18.67 & 1.55 & 5.37 & -- & -- & -- & -- & \\
\hline $\mathrm{H}$ & 0.61 & 0.61 & 2.09 & -- & -- & -- & -- & \\
\hline I & 42.34 & 0.33 & 1.74 & -- & -- & -- & -- & \\
\hline $\mathrm{Zr}$ & 17.50 & 0.19 & 1.00 & -- & -- & -- & -- & \\
\hline $\mathrm{O}$ & 20.88 & 1.31 & 4.51 & -- & -- & -- & -- & \\
\hline
\end{tabular}




\begin{tabular}{|l|c|c|c|c|c|c|c|c|}
\hline \multicolumn{2}{|c|}{$\mathbf{3 0 \%} \mathbf{I}_{2}$-bdc direct, pre ball-milling } & \multicolumn{5}{c|}{$\mathbf{3 0 \%} \mathbf{I}_{2}$-bdc direct, posty ball-milling* } \\
\hline Element & $\begin{array}{c}\text { \% } \\
\text { mass }\end{array}$ & moles & $\begin{array}{c}\text { Ratio, } \\
\text { normalized } \\
\text { to Zr }\end{array}$ & \% mass & moles & $\begin{array}{c}\text { Ratio, } \\
\text { normalized } \\
\text { to Zr }\end{array}$ & $\begin{array}{c}\text { Average } \\
\text { ratio }\end{array}$ & $\begin{array}{c}\text { Standard } \\
\text { Deviation }\end{array}$ \\
\hline $\mathrm{C}$ & 24.42 & 2.03 & 7.03 & -- & -- & -- & -- & \\
\hline $\mathrm{H}$ & 1.35 & 1.34 & 4.63 & -- & -- & -- & -- & \\
\hline $\mathrm{I}$ & 16.53 & 0.13 & 0.45 & -- & -- & -- & -- & \\
\hline $\mathrm{Zr}$ & 26.40 & 0.29 & 1.00 & -- & -- & -- & -- & \\
\hline $\mathrm{O}$ & 31.30 & 1.96 & 6.76 & -- & -- & -- & -- & \\
\hline
\end{tabular}

*Sample not run, I:Zr ratios pre- and post-milling presumed to be the same

Table S4. Analytical data acquired from Galbraith Laboratories, Inc. Carbon and hydrogen amounts were assessed by combustion analysis (SOP ME-14). Zirconium was assessed by inductively coupled plasma atomic emission spectrometry (SOP ME-70), and iodine was assessed by either ion selective electrode analysis (SOP E53-4) or a volumetric titration method (SOP E35-2). Volumetric titration is ideal for high iodine-content samples, and was only possible in one case starred above in which a large sample quantity was available. The average relative standard deviation of $11 \%$ observed for the I:Zr ratios across all samples was comparable to reported expected uncertainties and RSDs in the data for the employed SOPs. Oxygen was determined by subtraction, assuming no other elements were present. A control sample without iodine present was also included to ensure a proper cleaning procedure of the ball-mill with no sample carry-over between sample milling.

\begin{tabular}{|l|l|l|l|}
\hline Sample & $\begin{array}{l}\text { BET Surface Area }\left(\mathrm{m}^{2} / \mathrm{g}\right), \\
\text { Pre-ball-mill }\end{array}$ & $\begin{array}{l}\text { BET Surface Area } \\
\left(\mathrm{m}^{2} / \mathrm{g}\right), \text { Post-ball-mill }\end{array}$ & $\begin{array}{l}\% \text { Surface Area retained, } \\
\text { post-ball-mill }\end{array}$ \\
\hline $\begin{array}{l}\text { UiO-66-I, } \\
5 \text { day PSE }\end{array}$ & 1070 & 20 & $2 \%$ \\
\hline $\begin{array}{l}\text { UiO-66-I } 2, \\
5 \text { day PSE }\end{array}$ & 920 & 30 & $3 \%$ \\
\hline
\end{tabular}

Table S5. BET surface area measurements from nitrogen sorption experiments performed on selected post-ball-milled samples. 

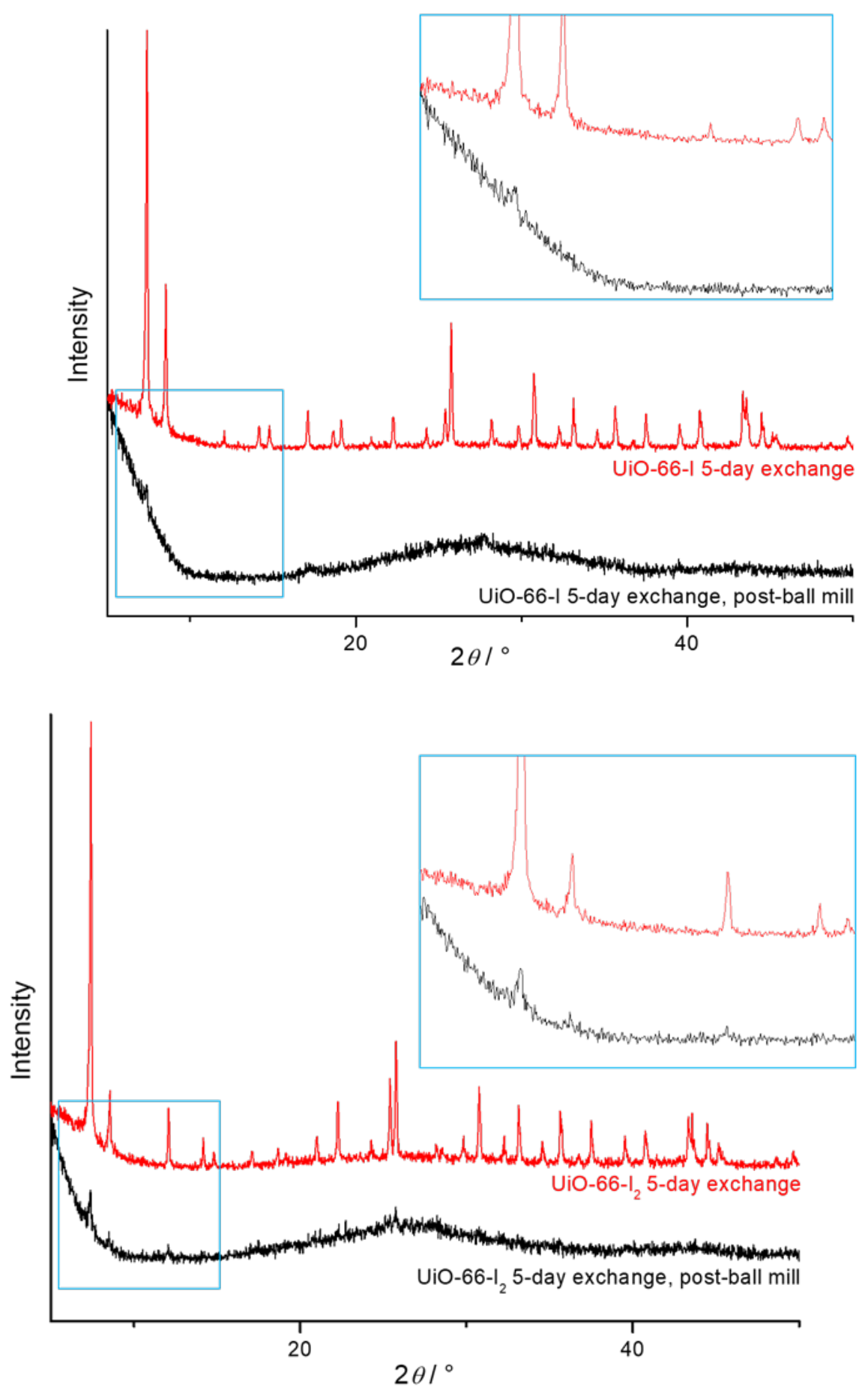

Figure S1. PXRD powder patterns of the ball-milled samples both before and after ball-milling, showing the total destruction of the MOF's crystallinity, in both a) UiO-66-I 5-day PSE sample and b) UiO-66- $\mathrm{I}_{2}$ 5-day PSE sample. 


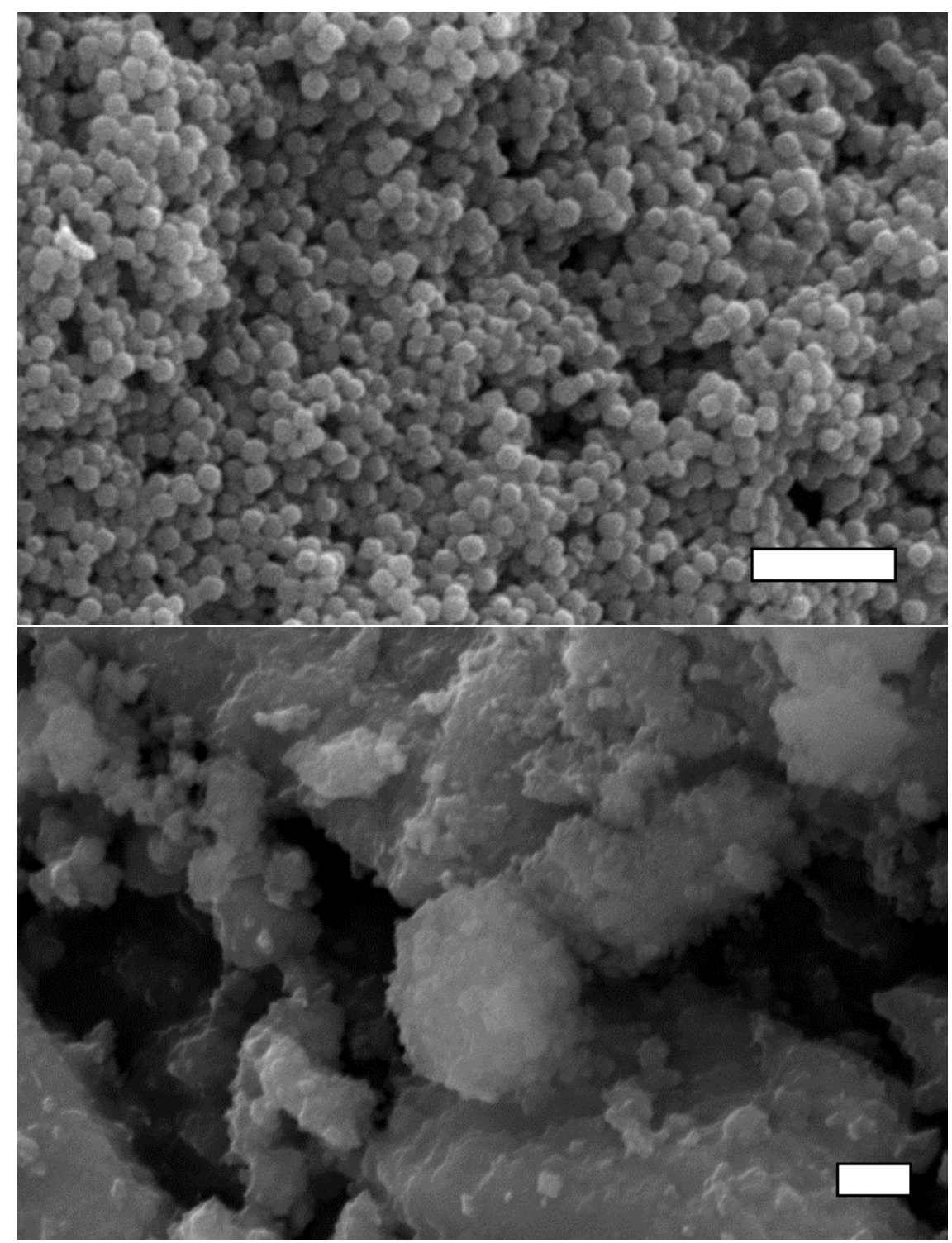

Figure S2. SEM images of a) UiO-66-I 5-day PSE starting particles and b) the same sample, post-ball-milling, showing the complete loss of spherical particle character. Scale bars are $1 \mu \mathrm{m}$. 


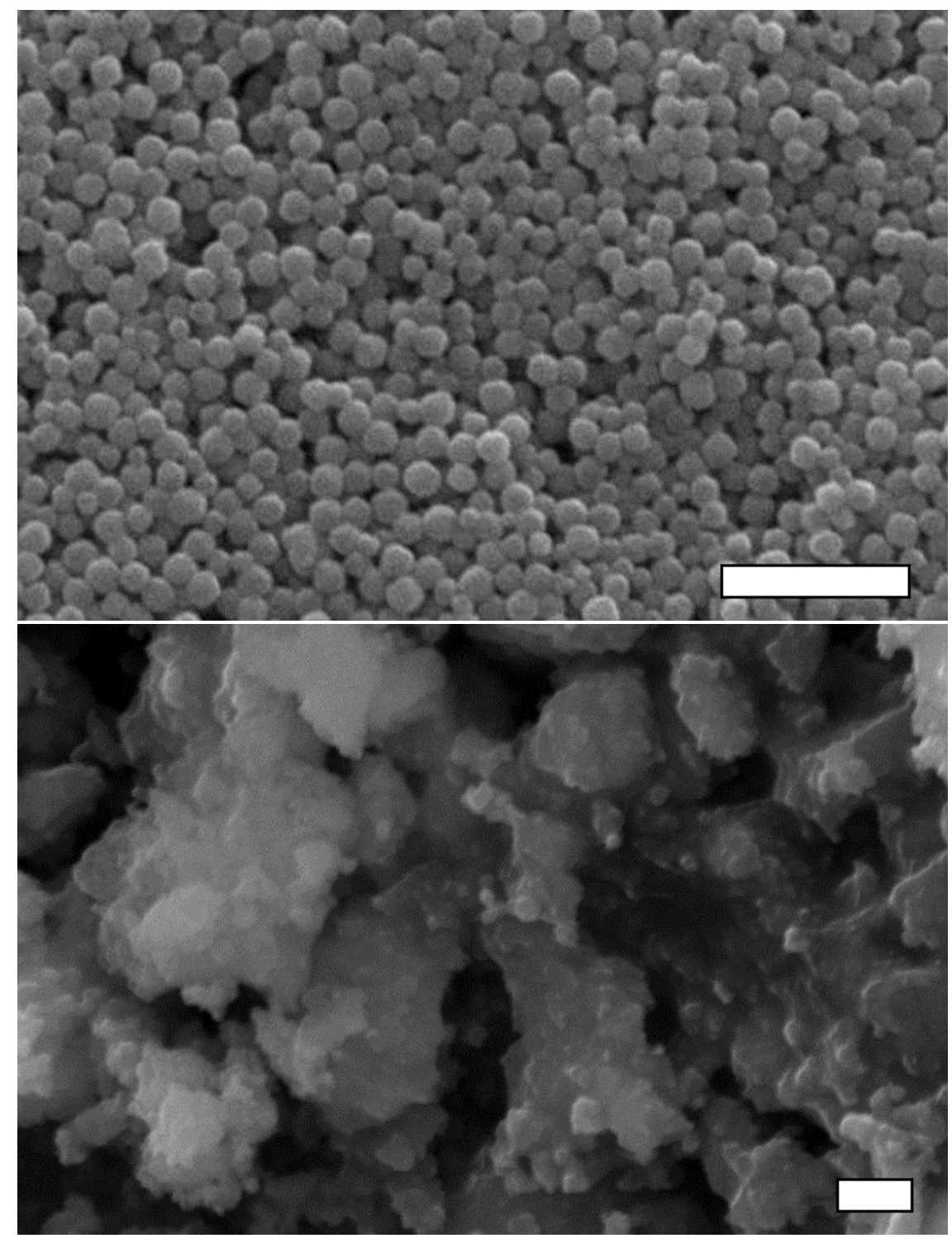

Figure S3. SEM images of a) UiO-66- $\mathrm{I}_{2}$ 5-day PSE starting particles and b) the same sample, post-ball-milling, showing the complete loss of spherical particle character. Scale bars are $1 \mu \mathrm{m}$. 


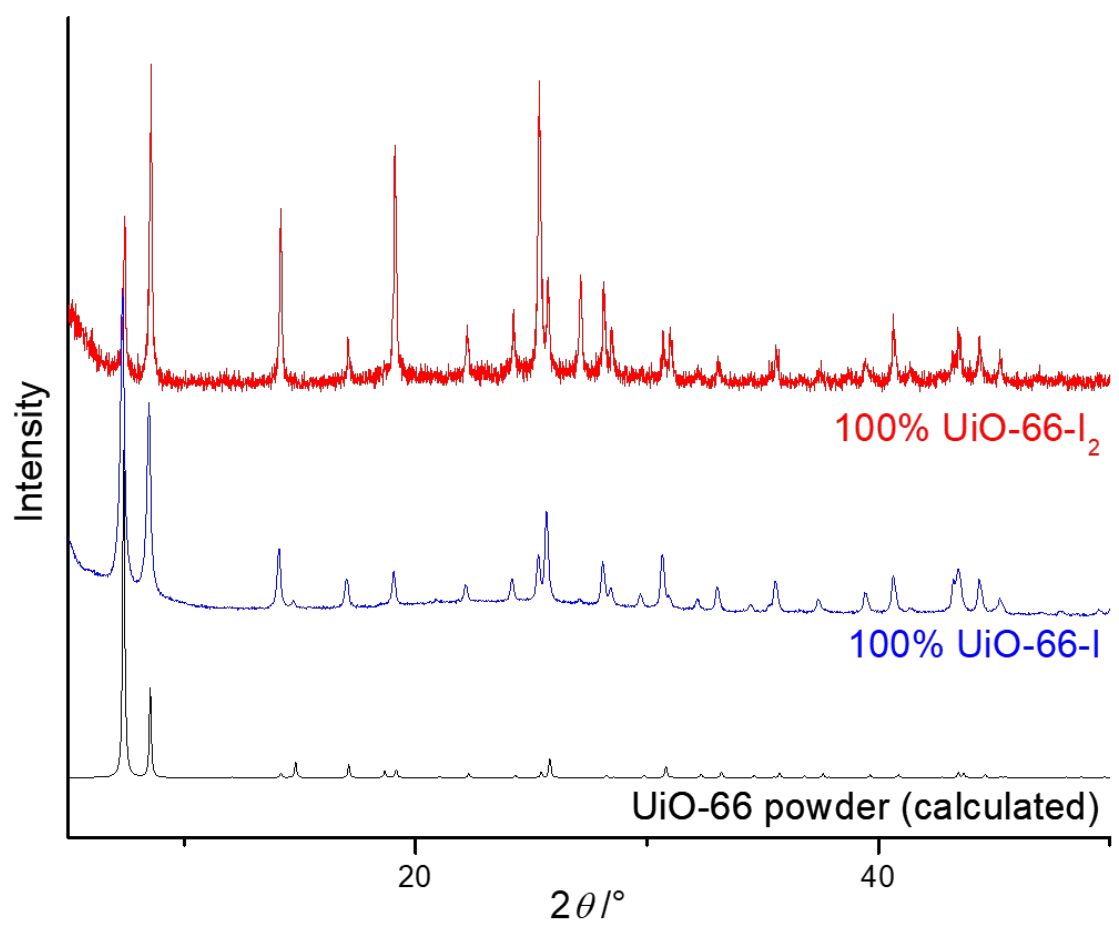

Figure S4. PXRD pattern of UiO-66 (black trace) is compared to as-synthesized MOFs using 2iodobenzene-1,4-dicarboxylic acid (blue trace) and 2,5-diiodobenzene-1,4-dicarboxylic acid (red trace) linkers. Small amorphous regions exist above the baseline between $20-30^{\circ} 2 \theta$ in red and blue traces, indicating amorphous content in both UiO-66-I and UiO-66- $\mathrm{I}_{2}$. Note large differences in peak intensity in the as-synthesized diiodo-substituted MOF (red trace). Although all peaks are present, indicating UiO-66 crystal structure formation, these peak intensity differences in UiO-66- $\mathrm{I}_{2}$ indicate overall worse crystallinity in this material than in the others shown. 


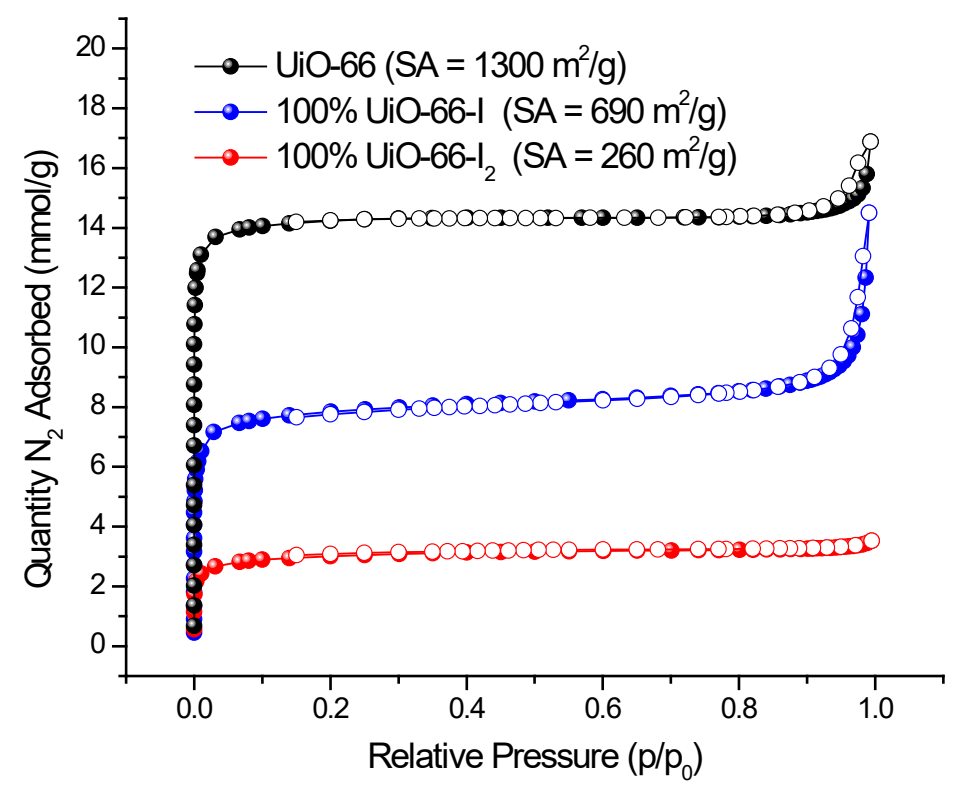

Figure S5. Nitrogen isotherms of single- and double-substituted iodine-functionalized MOFs shown compared to native UiO-66 nitrogen isotherm (black trace). Calculated BET surface area values are listed on the graph. The low surface area of UiO-66- $\mathrm{I}_{2}$ shown indicates the presence of large amounts of amorphous, non-porous character in this sample, corresponding to the poor crystallinity seen in the PXRD trace (Figure S4). 

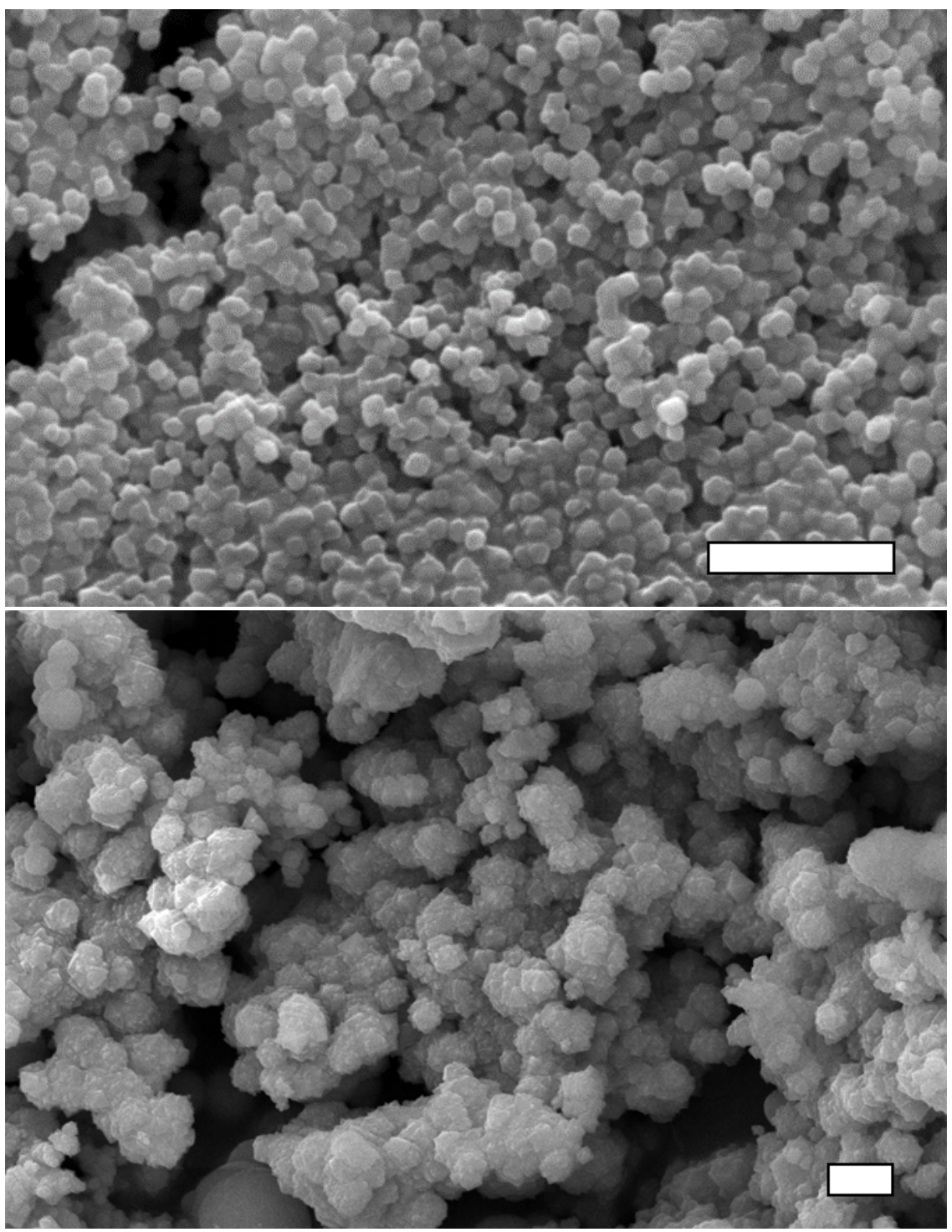

Figure S6. SEM images of a) 100\% UiO-66-I and b) 100\% UiO-66- $\mathrm{I}_{2}$. The I-bdc linker gives a regular, roughly spherical particle morphology, while the $\mathrm{I}_{2}$-bdc linker shows MOF crystallites of irregular size and shape. Scale bars are $1 \mu \mathrm{m}$. 


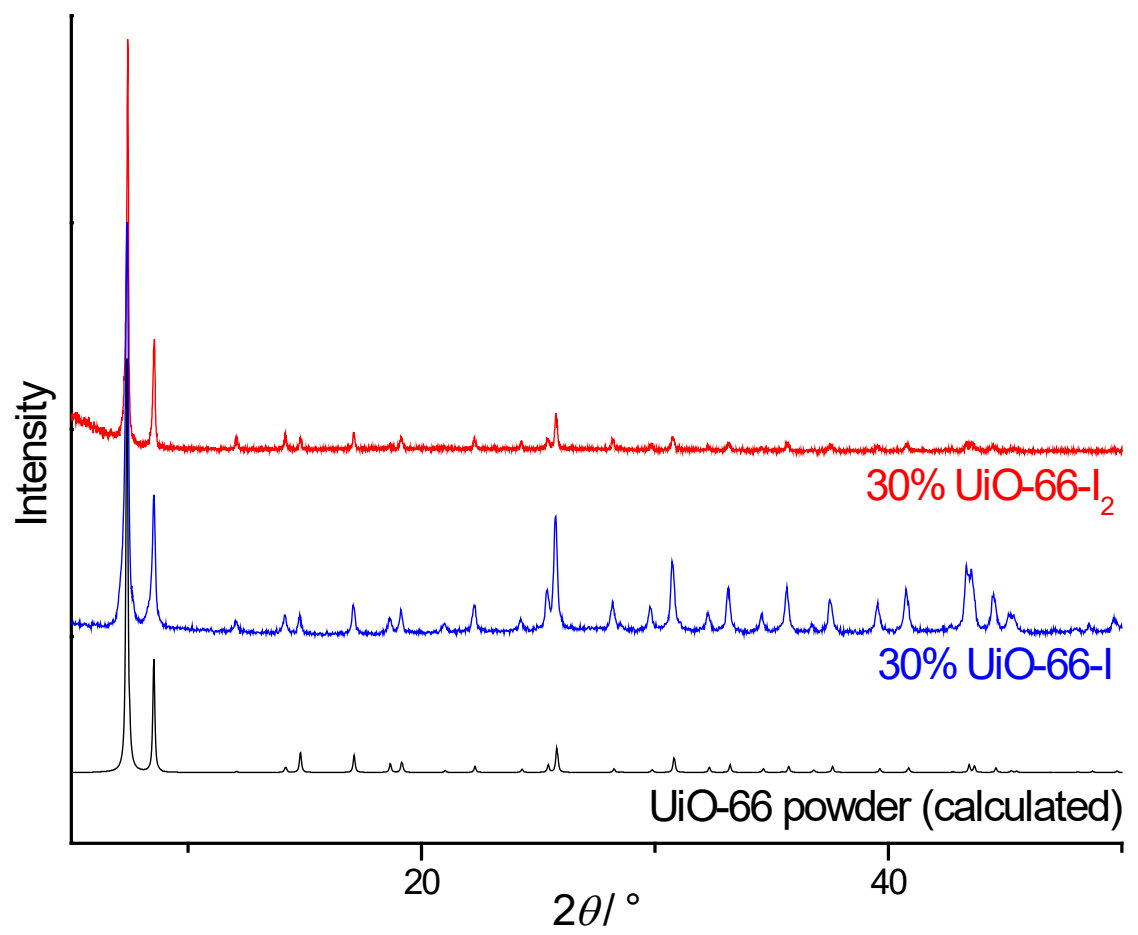

Figure S7. PXRD patterns show excellent crystallinity is maintained in both mixed-linker MOFs (red and blue traces) compared to the calculated UiO-66 powder pattern (black trace).

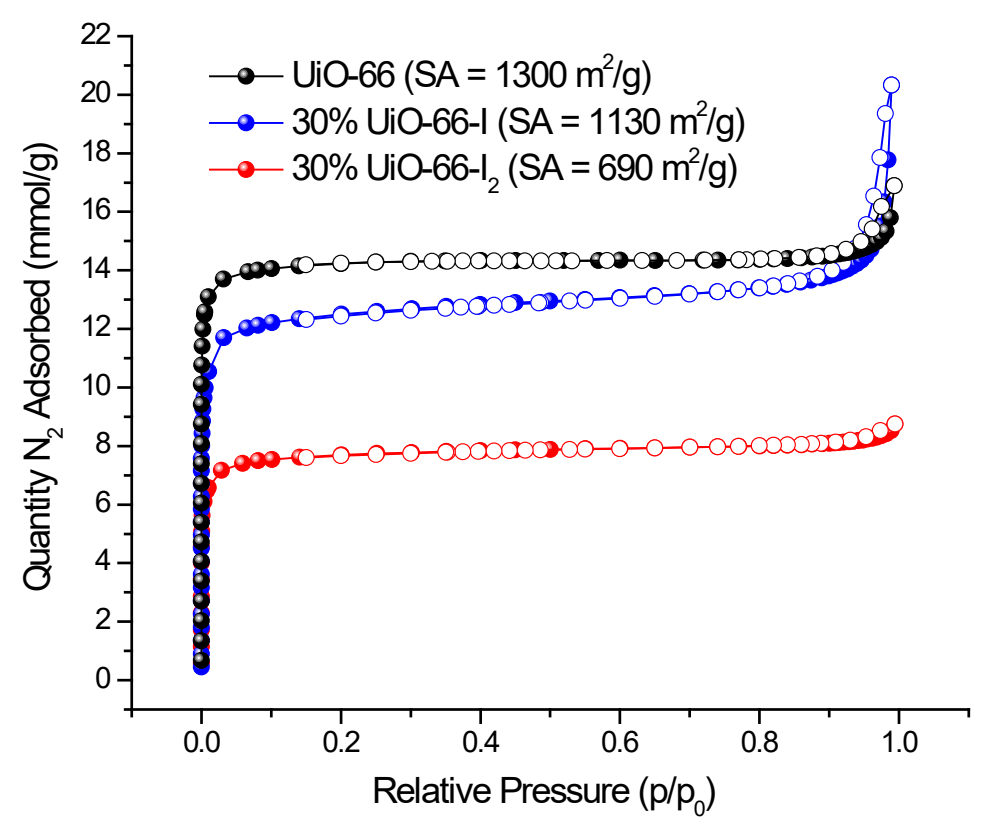

Figure S8. $\mathrm{N}_{2}$ sorption isotherms of mixed-linker direct-synthesis MOFs using 2-iodobenzene1,4-dicarboxylic acid (blue trace) and 2,5-diiodobenzene-1,4-dicarboxylic acid acid (red trace) are shown. The higher weight of the extra iodine content and the greater pore-filling seen by that ligand likely explain the disparities in surface area. 


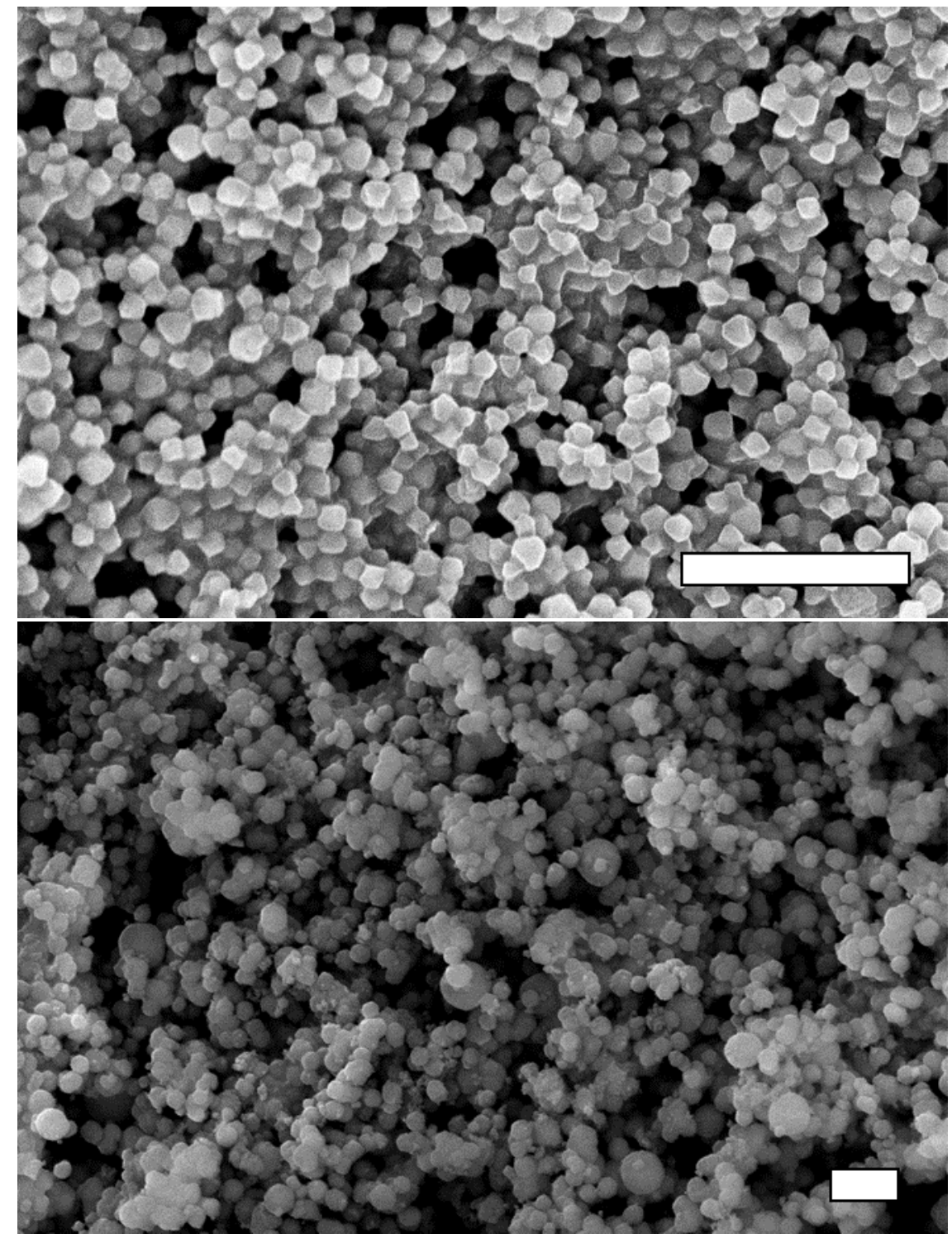

Figure S9. SEM images of mixed-ligand direct-synthesis MOFs using a) 2-iodobenzene-1,4carboxylic acid and b) 2,5-diiodobenzene-1,4-dicarboxylic acid acid are shown. Scale bars are both $1 \mu \mathrm{m}$. While both show spherical morphology, particles are much more regular in size and show sharp facets using the smaller 2-iodobenzene-1,4-dicarboxylic acid. 


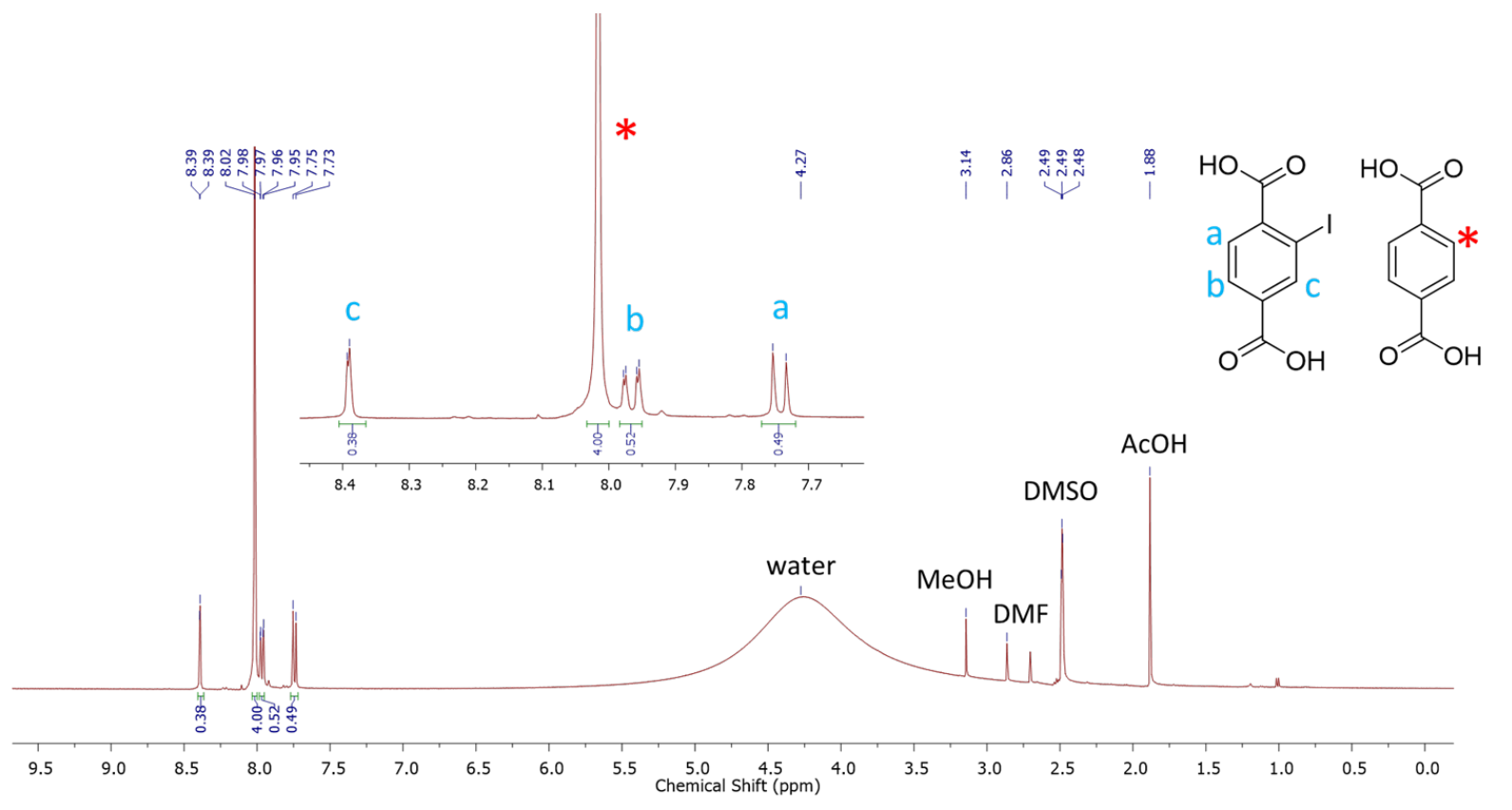

Figure S10. NMR spectrum of mixed-ligand direct synthesis product using 30\% 2-iodobenzene1,4-dicarboxylic acid and 70\% benzene-1,4-dicarboxylic acid. Peaks are assigned as shown. Integration relative to the four protons of benzene-1,4-dicarboxylic acid shows $33 \%$ of linkers in the MOF are functionalized.

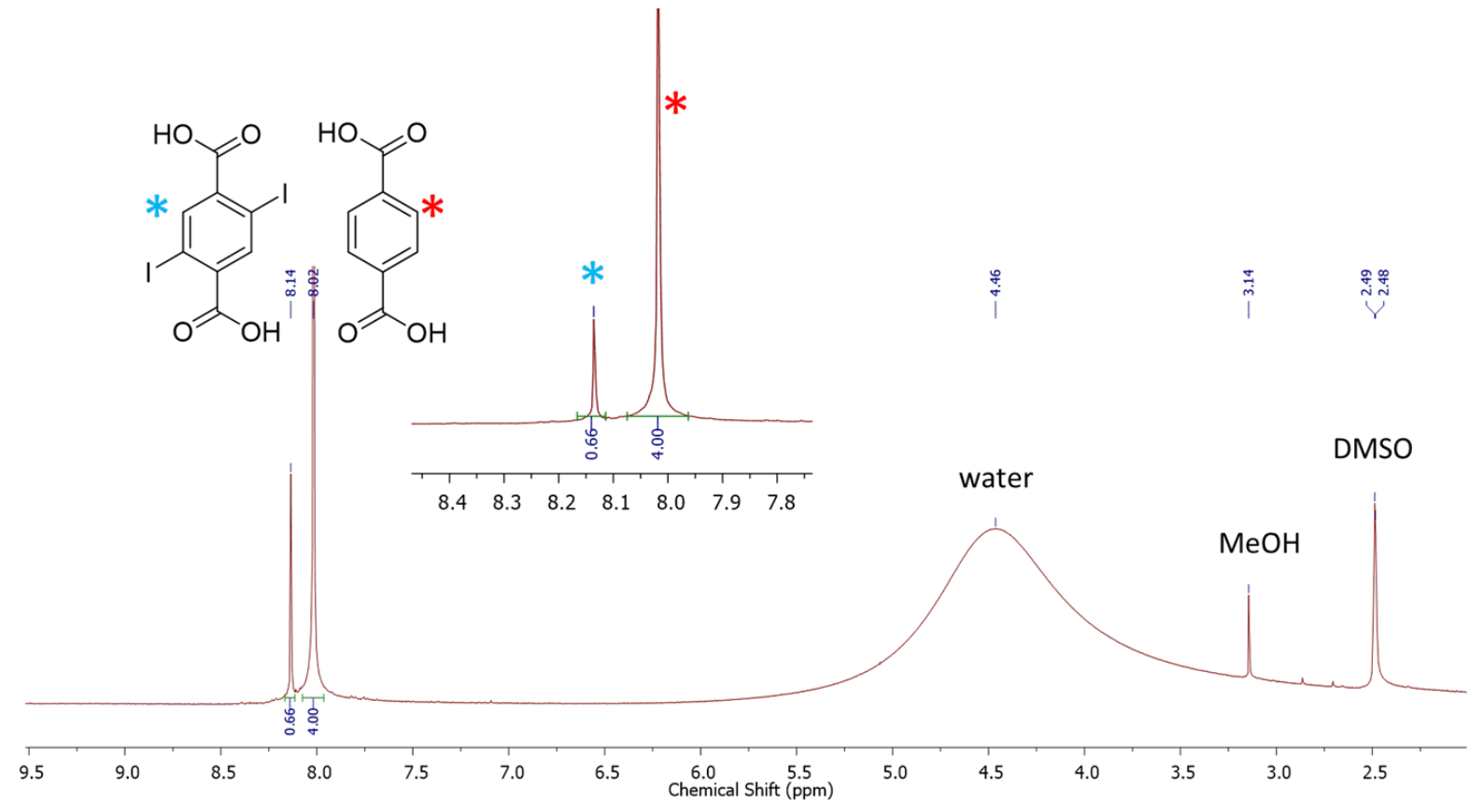

Figure S11. NMR spectrum of mixed-ligand direct synthesis product using 30\% 2,5diiodobenzene-1,4-dicarboxylic acid acid and 70\% benzene-1,4-dicarboxylic acid. Peaks are assigned as shown. Integration relative to the four protons of benzene-1,4-dicarboxylic acid shows $25 \%$ of linkers in the MOF are functionalized. 


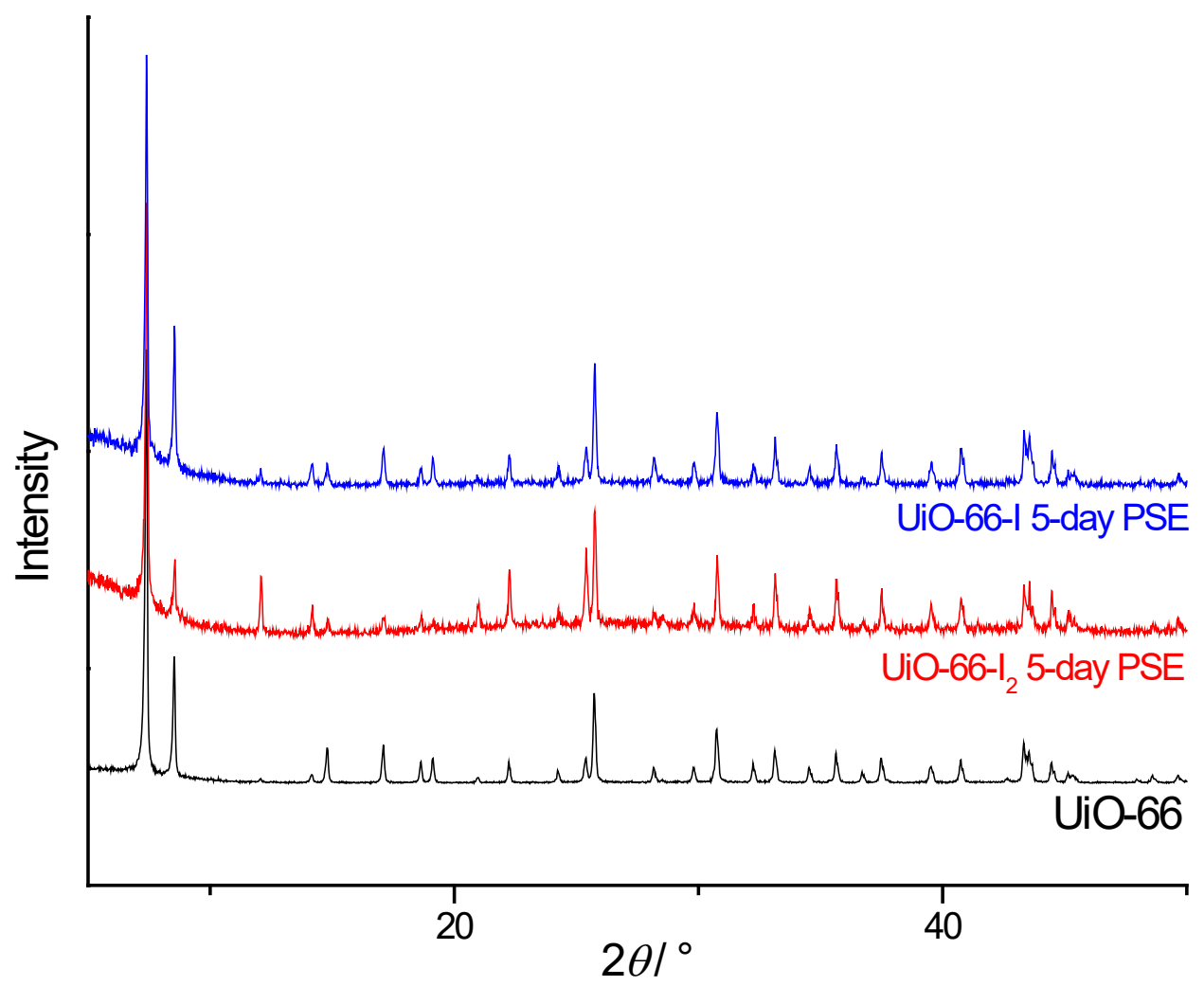

Figure S12. PXRD trace of 5-day PSE products with both I-bdc and $\mathrm{I}_{2}$-bdc, showing good retention of crystallinity after PSE.

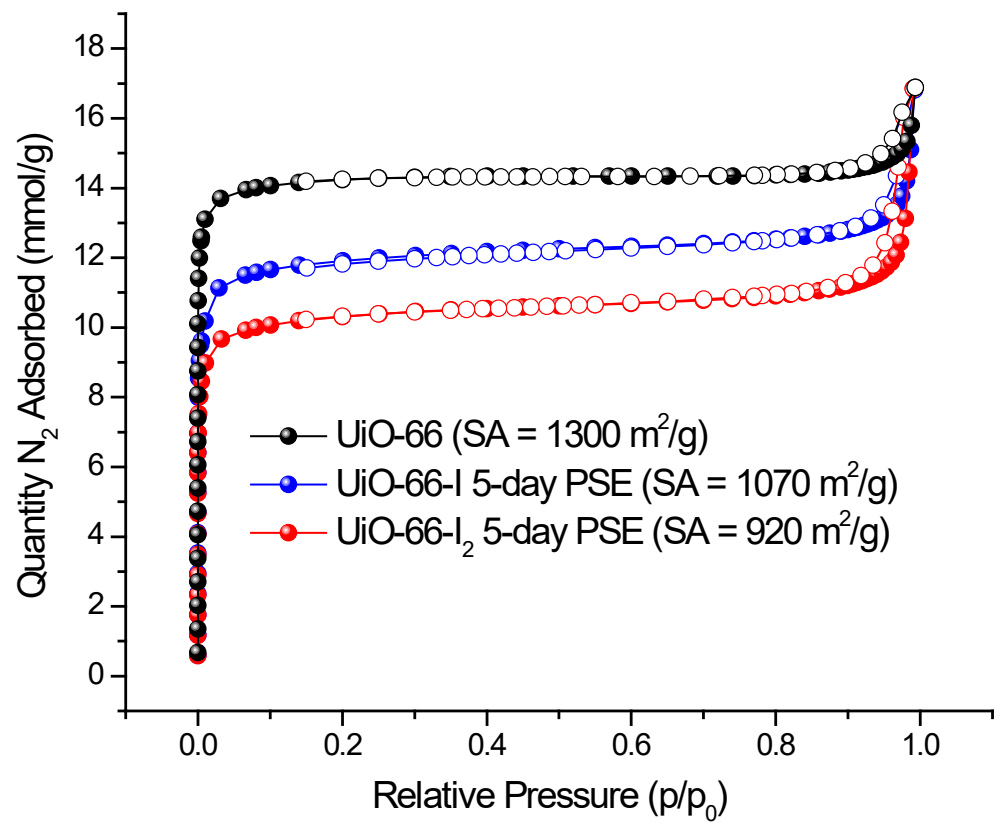

Figure S13. Nitrogen uptake isotherms demonstrating differing nitrogen uptake of PSE products after PSE, due to the incorporation of heavier/bulkier iodine-substituted ligands. 


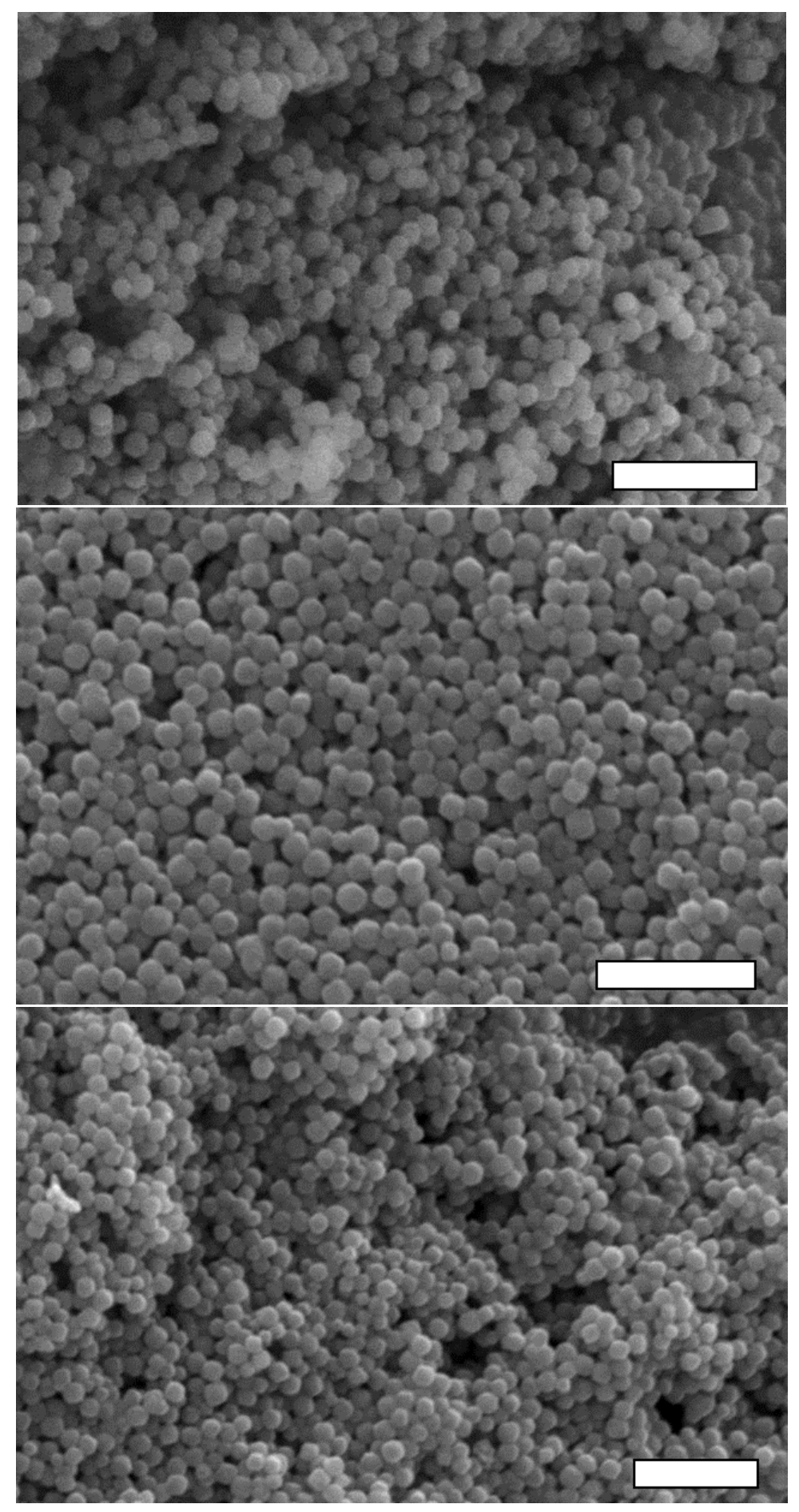

Figure S14. SEM images comparing a) starting UiO-66, b) 5-day PSE UiO-66- $\mathrm{I}_{2}$, and c) 5-day PSE UiO-66-I. All particles appear similar in size and shape, indicating no particle breakdown during PSE. Scale bars are $1 \mu \mathrm{m}$. 


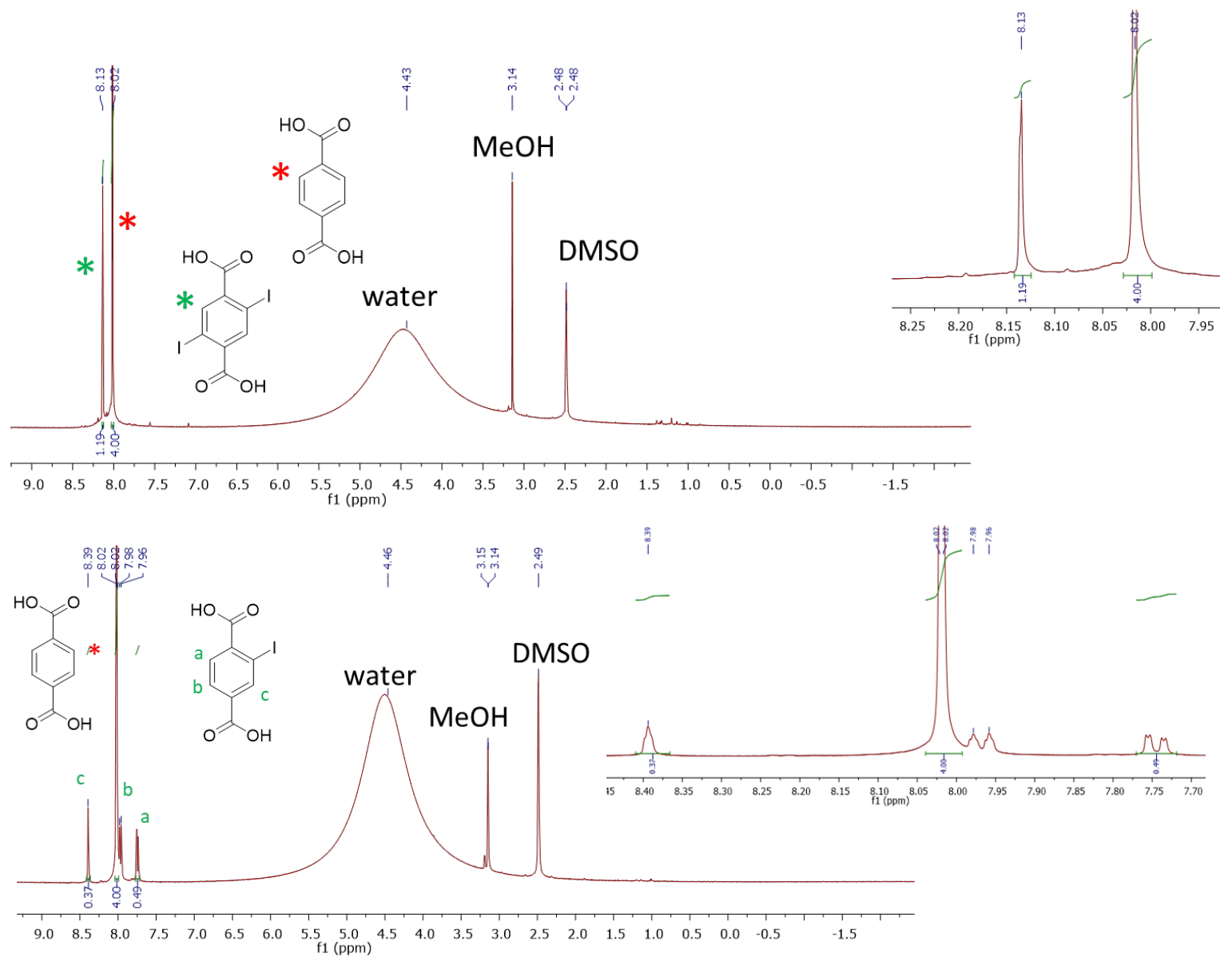

Figure S15. HF digestion products of a) UiO-66- $\mathrm{I}_{2}$ 5-day PSE and b) UiO-66-I 5-day PSE shown by NMR. Each ligand's separate peaks can be quantified relative to each other to determine the amount of exchange that took place. The percent exchange is $37 \%$ in the case of $\mathrm{I}_{2}$-bdc and $33 \%$ in the case of I-bdc. 


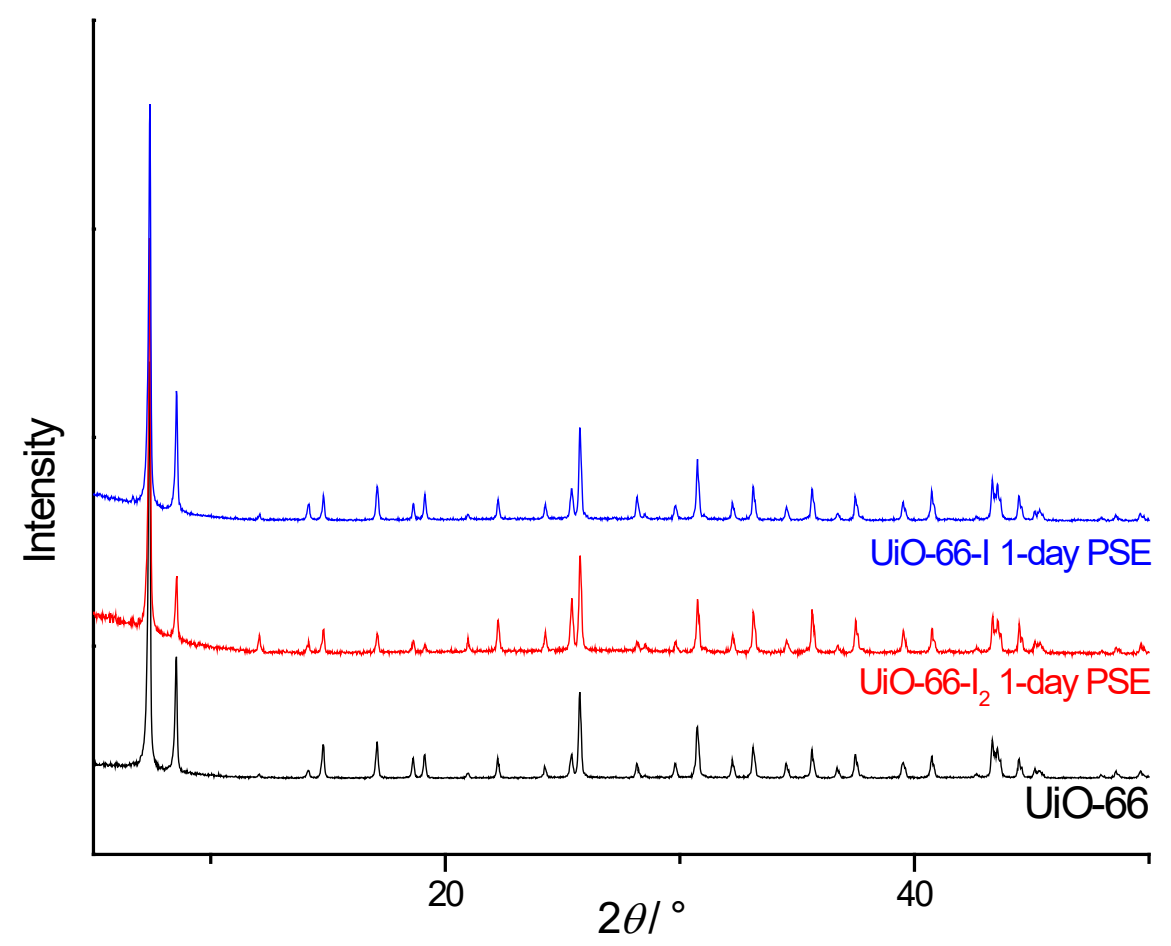

Figure S16. PXRD trace of 1-day PSE products with both I-bdc and $\mathrm{I}_{2}$-bdc, showing good retention of crystallinity after PSE.

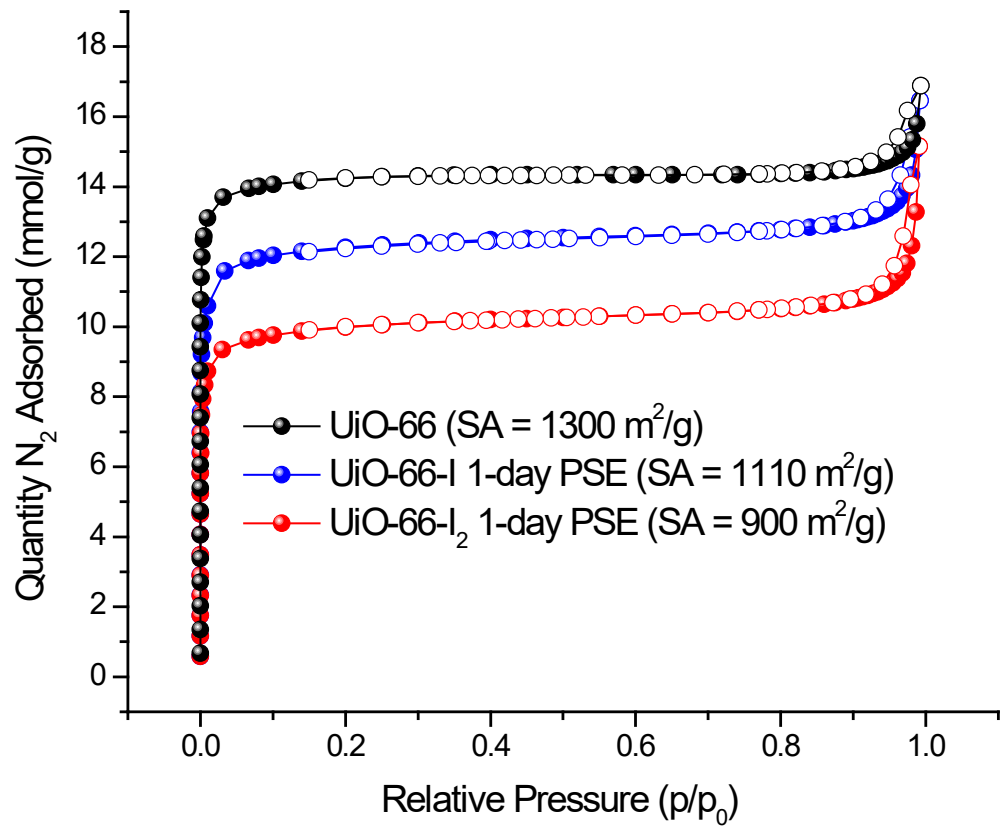

Figure S17. Nitrogen uptake isotherms demonstrating differing nitrogen uptake of PSE products after PSE, due to the incorporation of heavier/bulkier iodine-substituted ligands. 

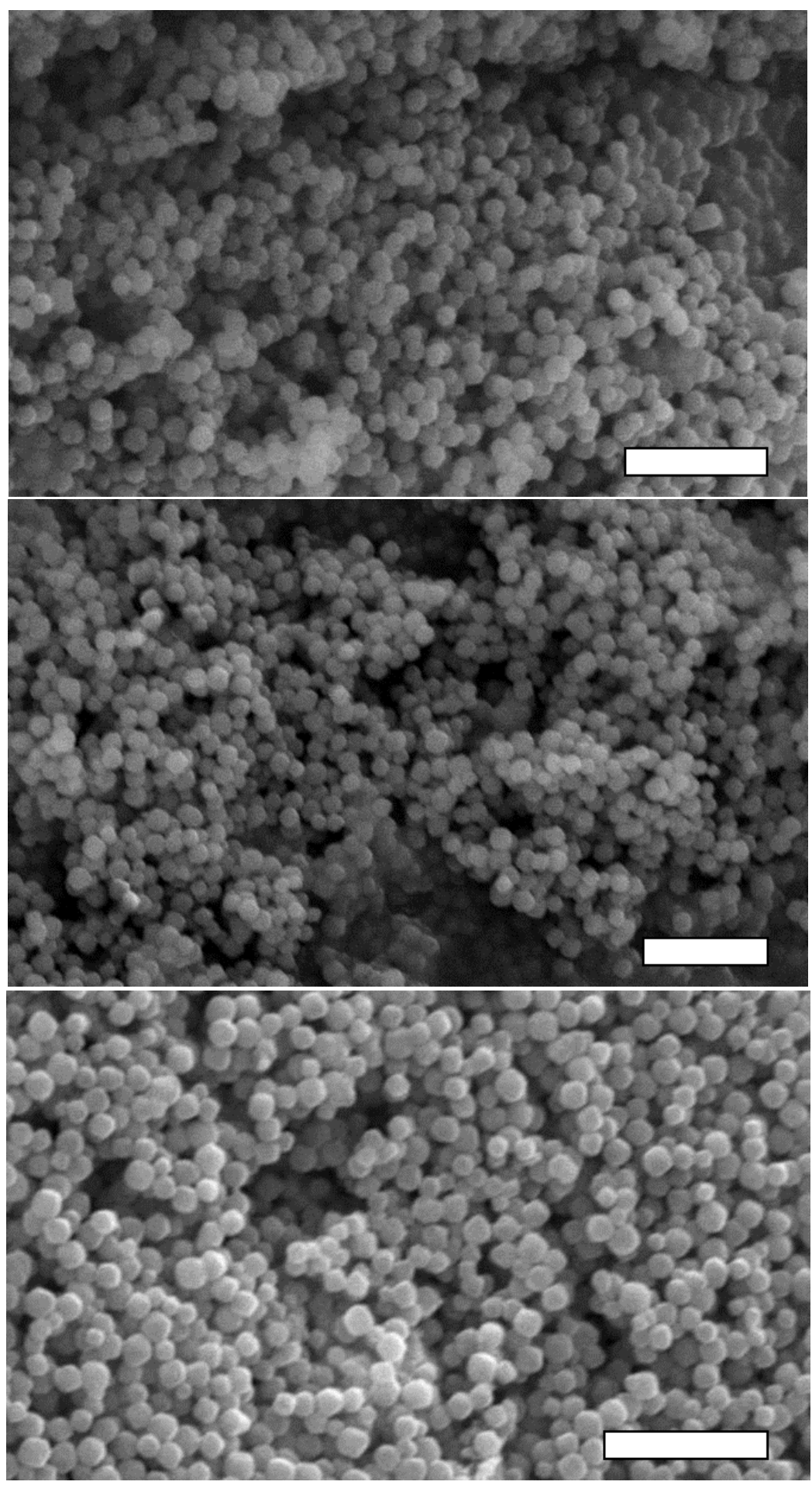

Figure S18. SEM images comparing a) starting UiO-66, b) 1-day PSE UiO-66- $\mathrm{I}_{2}$, and c) 1-day PSE UiO-66-I. All particles appear similar in size and shape, indicating no particle breakdown during PSE. Scale bars are $1 \mu \mathrm{m}$. 


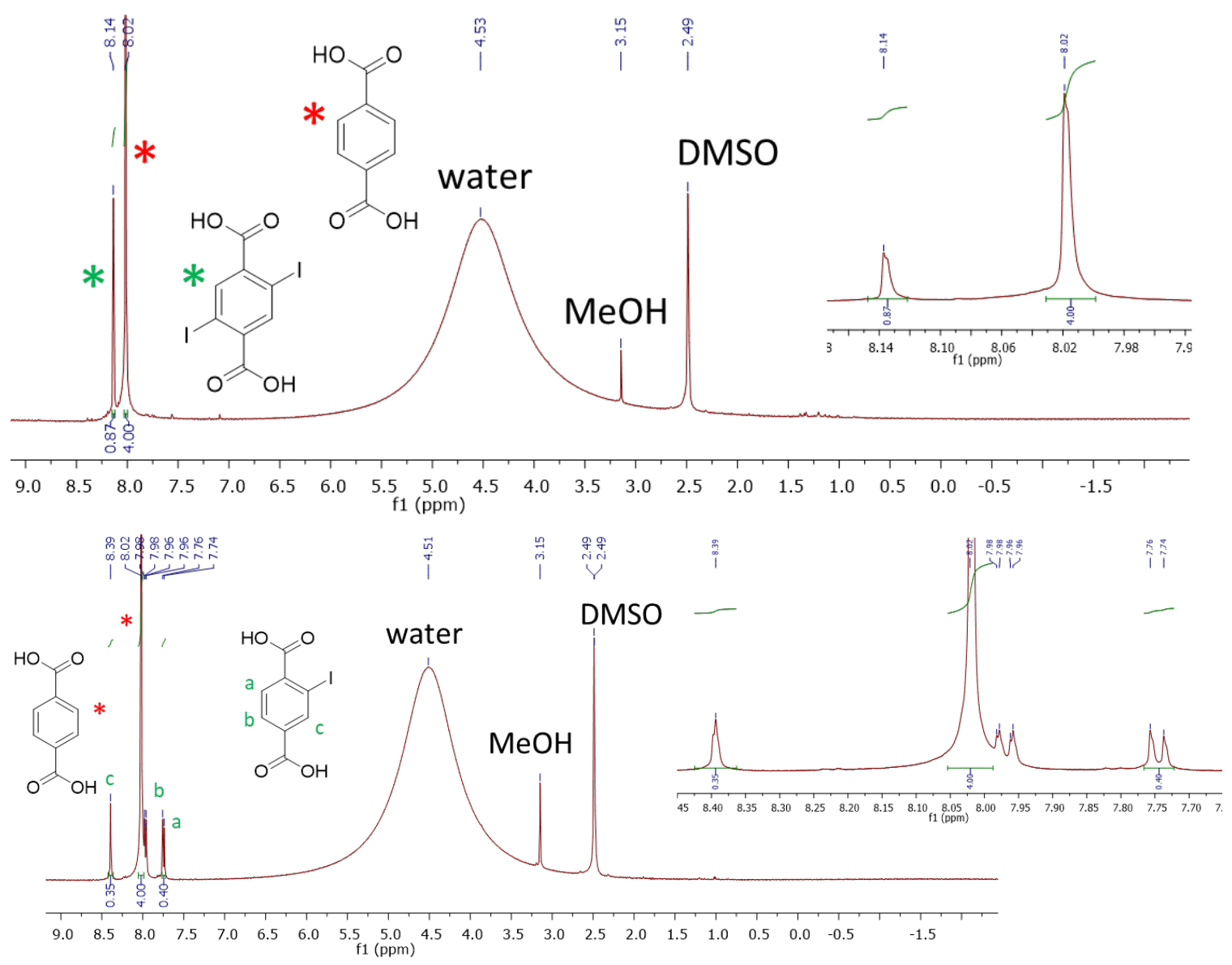

Figure S19. HF digestion products of a) UiO-66-I2 1-day PSE and b) UiO-66-I 1-day PSE. Each ligand's separate peaks can be quantified relative to each other to determine the amount of exchange that took place. The percent exchange is $30 \%$ in the case of $I_{2}$-bdc and $29 \%$ in the case of I-bdc. 


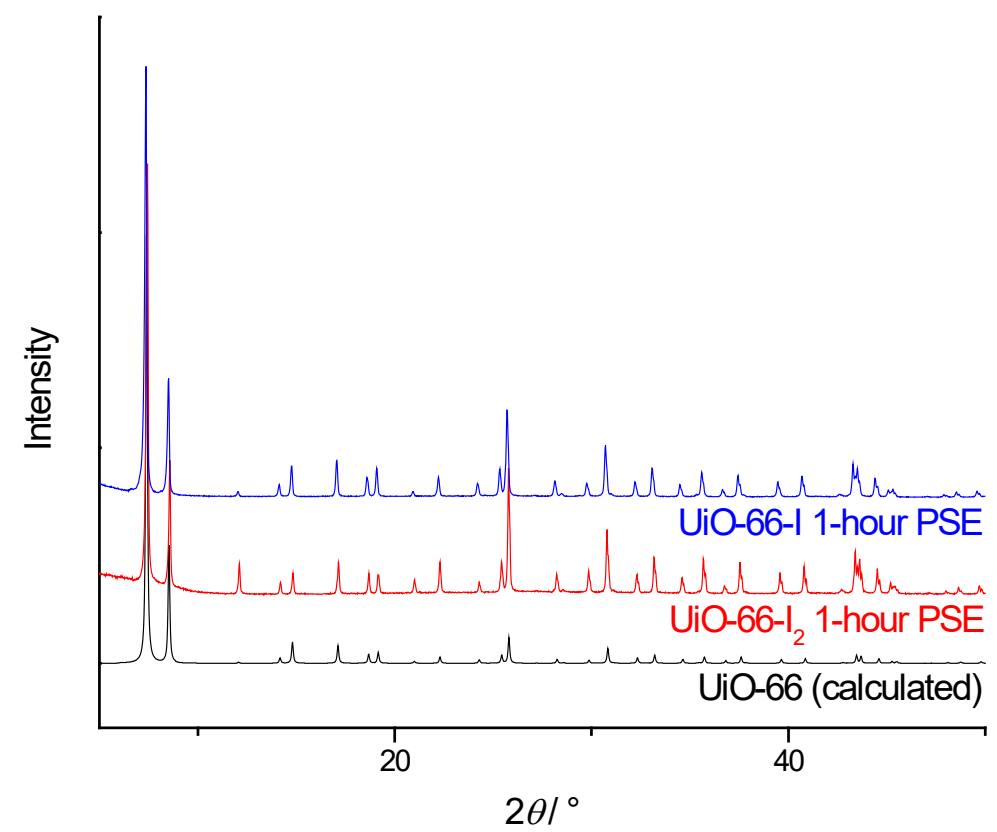

Figure S20. PXRD trace of 1-hour PSE products with both I-bdc and $\mathrm{I}_{2}$-bdc, showing good retention of crystallinity after PSE.

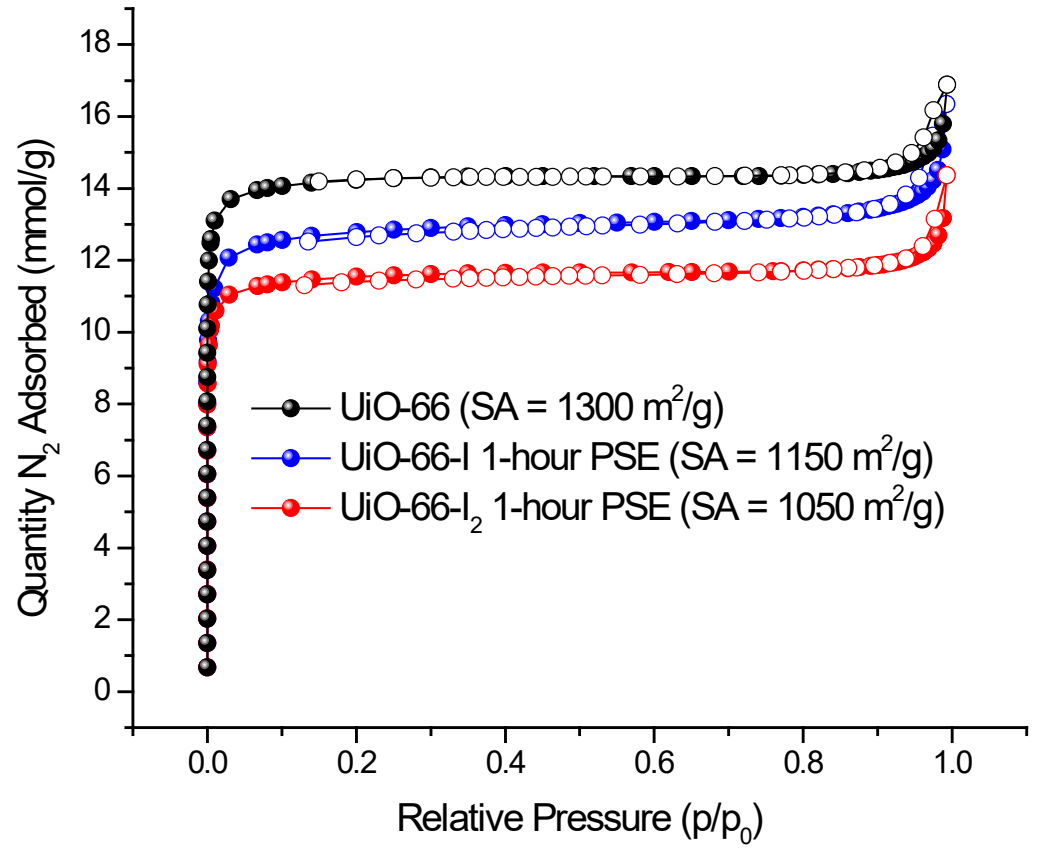

Figure S21. Nitrogen uptake isotherms demonstrating differing nitrogen uptake of PSE products after PSE, due to the incorporation of heavier/bulkier iodine-substituted ligands. 

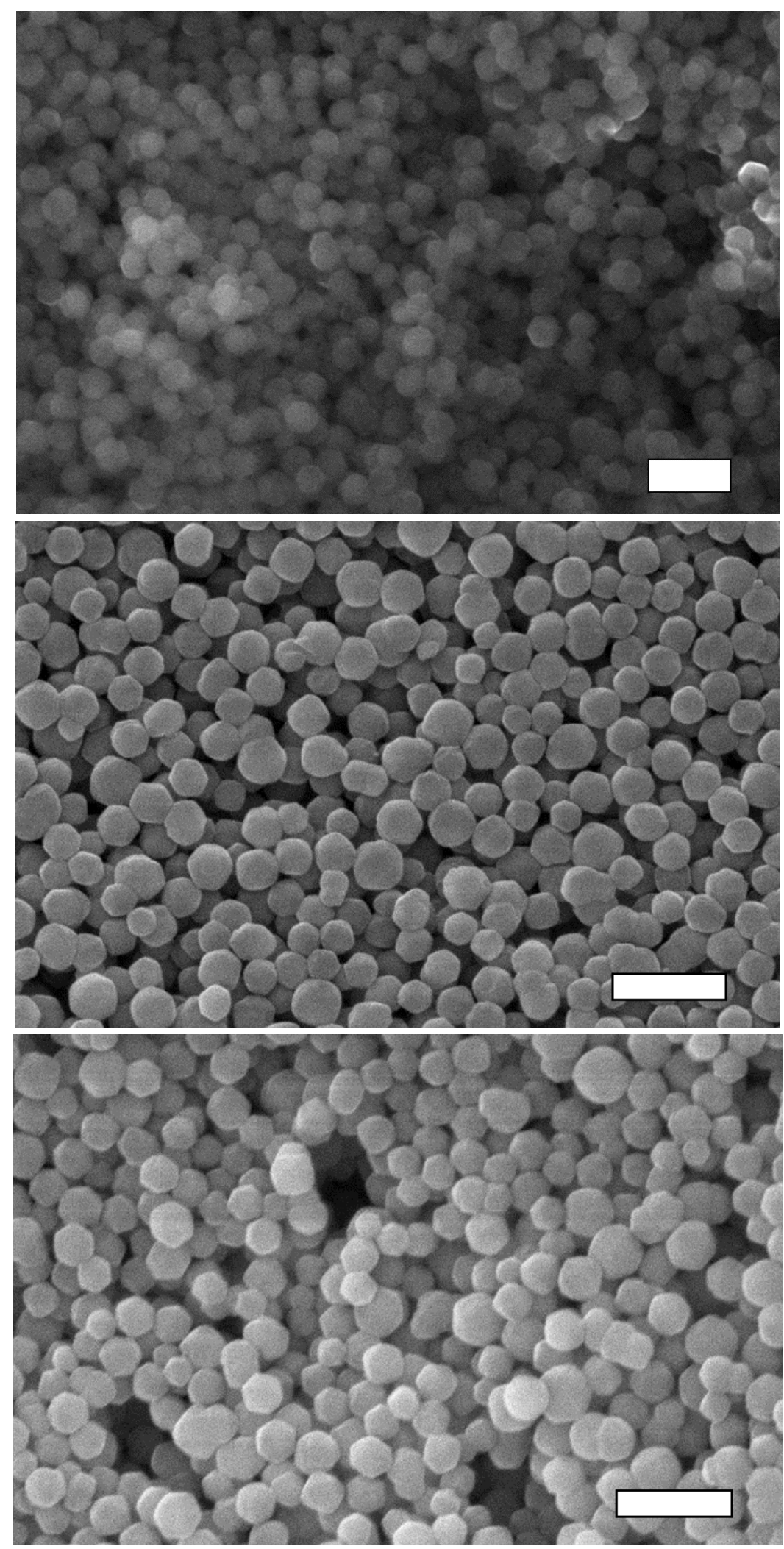

Figure S22. SEM images comparing a) starting UiO-66, b) 1-hour PSE UiO-66-I, and c) 1-hour PSE UiO-66- $\mathrm{I}_{2}$. All particles appear similar in size and shape, indicating no particle breakdown during PSE. Scale bars are $500 \mathrm{~nm}$. 

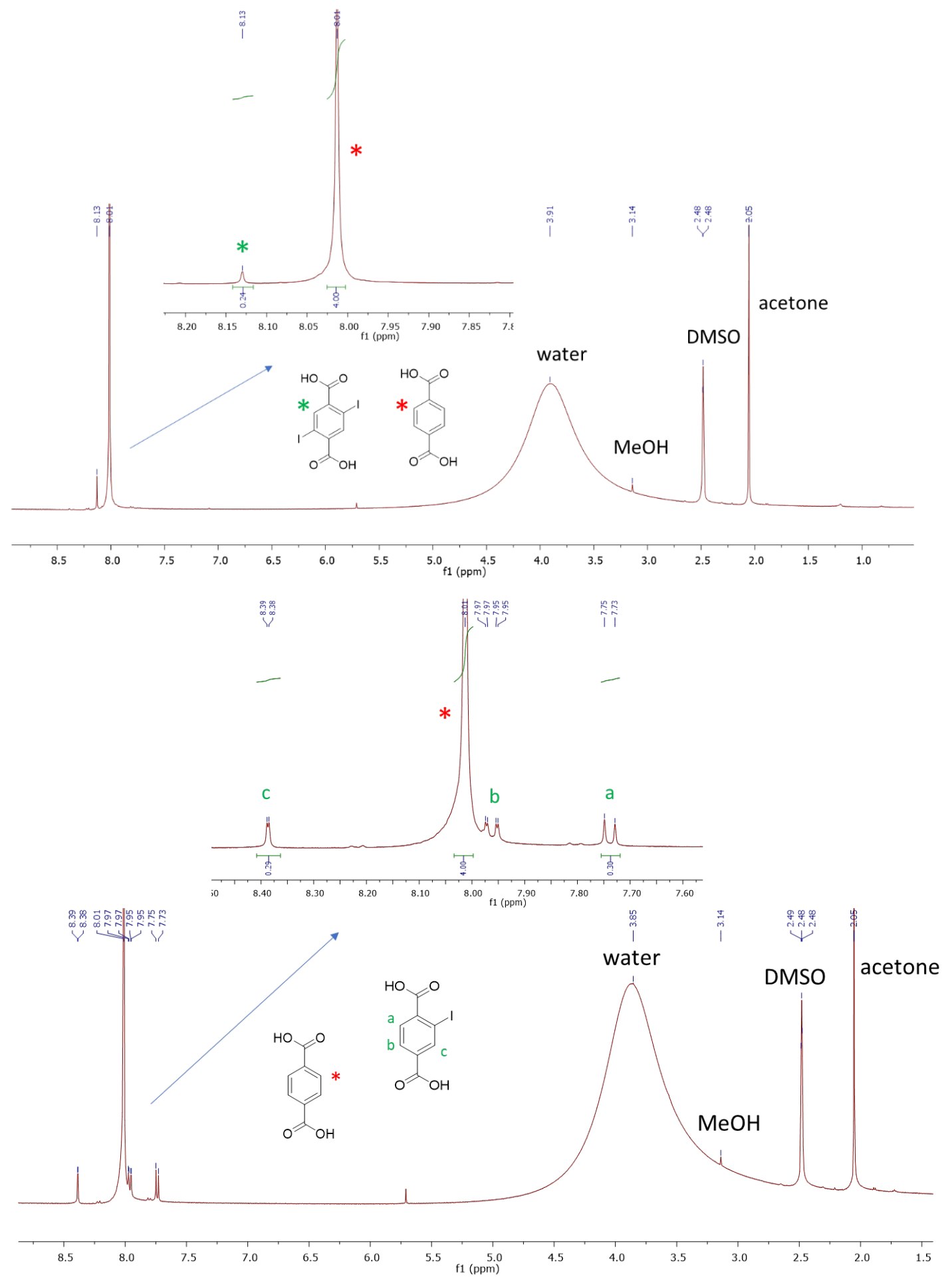

Figure S23. HF digestion products of a) UiO-66-I2 1-hour PSE and b) UiO-66-I 1-hour PSE. Each ligand's separate peaks can be quantified relative to each other to determine the amount of exchange that took place. The percent exchange is $11 \%$ in the case of $\mathrm{I}_{2}$-bdc and $23 \%$ in the case of I-bdc. 


\section{XPS of Ball-milled Samples}

We also examined the effect of ball-milling (intentional amorphization) on the iodine XPS peaks, shown in Figure S24. With a few notable exceptions, nearly all samples exhibited at least a minor increase in the presence of the lower binding-energy feature assigned above to under-coordinated ligands. Only minor increases in this feature, if any, were observed in the Ibdc samples upon ball-milling. Striking increases in the lower binding energy peaks were observed for all $\mathrm{I}_{2}$-PSE samples, with greater increases for longer PSE times. In contrast, these peaks decreased following ball-milling of the 100\% $\mathrm{I}_{2}$-PSE and 30\% $\mathrm{I}_{2}$-bdc/70\% bdc samples. The differences observed post-ball-milling in this study require further study to fully understand, however, the increased presence of a second iodine peak at lower binding energy in most cases following intentional amorphization supports its relation to undercoordinated linkers.

Interestingly, ball-milling has been used both to amorphize and synthesize UiO-66, 7,8 though the experimental conditions varied. Pore collapse resulting in amorphization was observed to occur in the absence of solvent upon milling pre-formed UiO-66 at $20 \mathrm{~Hz}$ for 20 minutes using a $3 \mathrm{~g}$ steel ball. Adding a small amount of solvent (roughly a few hundred microliters solvent per hundred milligram reactant species) to appropriate starting zirconium precursor clusters and linker molecules led to the formation of $\mathrm{UiO}-66$ upon milling at $30 \mathrm{~Hz}$ for 75 minutes using a $3.5 \mathrm{~g}$ zirconia ball. Remarkably, despite the seemingly higher energy in the latter case, synthesis is achieved without pore collapse. The authors of the amorphization study point to the use of pore filling (via the presence of solvent) to prevent pore collapse, and indeed the authors of the synthetic work note that the synthesis reaction does not proceed in the absence of solvent. In related work, a synchrotron study of ZIF-8 which employed in-situ XRD during a milling experiment uncovered an unexpected crystalline-amorphous-crystalline transformation starting from normal ZIF-8 and ending in a novel non-porous phase of ZIF-8 in the presence of water. ${ }^{9}$ Thus, the specific conditions of ball-milling, including filling of the pores by various species, starting materials, time, etc. can give rise to unexpected new crystalline (and amorphous) forms of metal organic frameworks. It is possible that the partially amorphous $\mathrm{I}_{2}-$ bdc samples have, in a sense, filled pores which then behave differently under ball-milling conditions compared to the more crystalline I-bdc samples. 

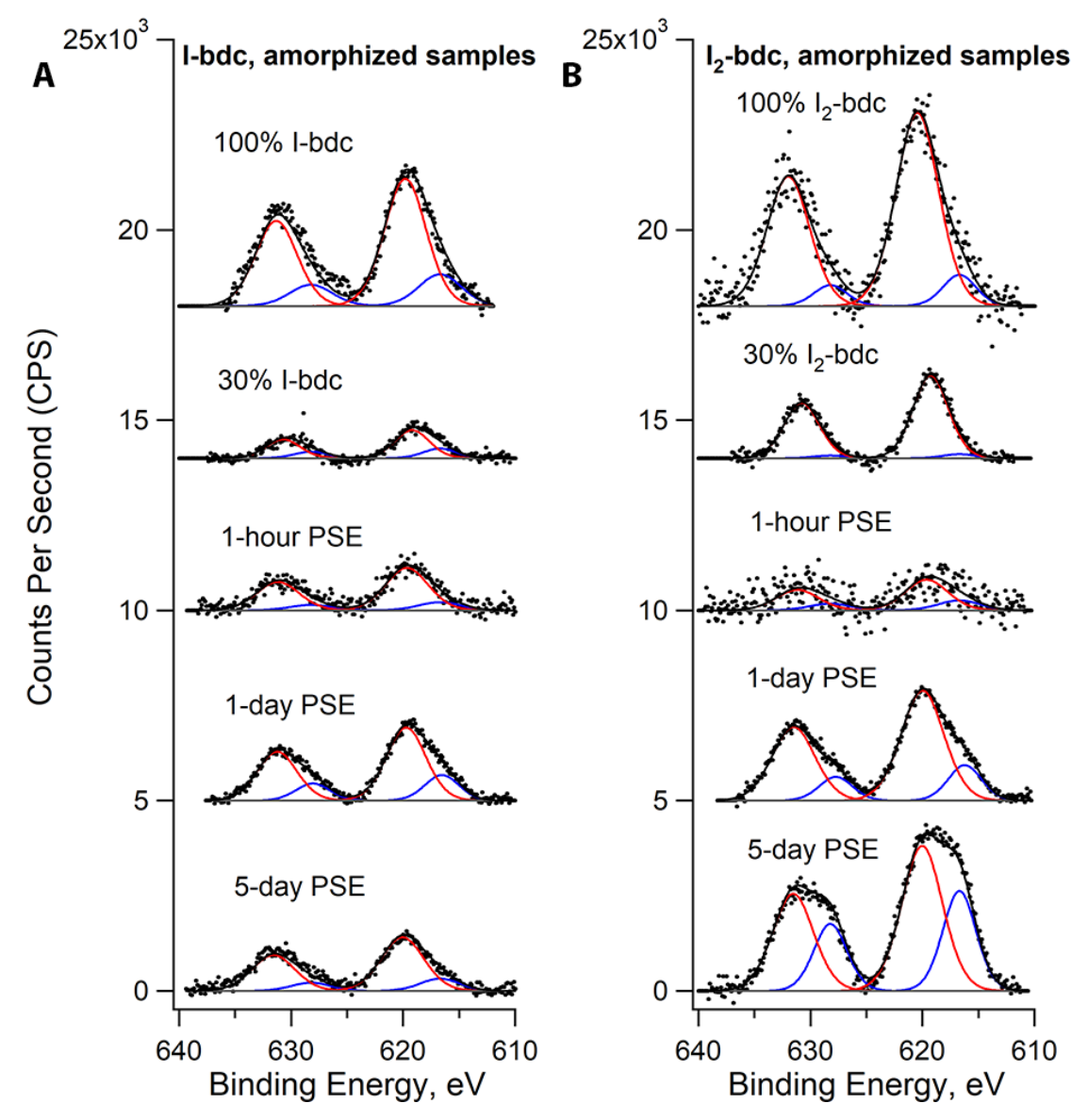

Figure S24. X-ray photoelectron spectra iodine 3d region collected after the amorphization of: (A) 100\% and 30\% I-bde UiO-66 direct synthesis samples, 5-day, 1-day, and 1-hour postsynthetic exchange I-bdc samples; and (B) Control 100\% and 30\% $\mathrm{I}_{2}$-bdc UiO-66 direct synthesis samples, 5-day, 1-day, and 1-hour postsynthetic exchange $\mathrm{I}_{2}$-bdc samples. Note that for ease of viewing the traces are offset on the y-axis following background subtraction.

\section{Comment on Angle Dependent XPS}

We should note that it is possible to perform depth analysis on surfaces using XPS by changing the angle of the sample relative to the detector orifice. Because escape depth of the photoelectrons produced is a constant, but the distance traveled from generation point below the surface to the surface will change as dictated by geometry, this can be used as a non-invasive tool to probe depth. Ideally, a wide range of angles (i.e., up to $60^{\circ}$ from a perpendicular orientation) would be probed on a continuous thin film, and this method has been successfully utilized to demonstrate the presence of a molecular overlayer on a particular MOF. ${ }^{10}$ The maximum depth range is up to the maximum photoelectron escape depth, achieved when the 
sample is held perpendicular to the detector. As the maximum photoelectron escape depth in this study is $\sim 5 \mathrm{~nm}$, a small fraction of the $\sim 250 \mathrm{~nm}$ particle size, we opted to use a combination of ion bombardment and ball-milling to obtain information more reflective of a bulk/surface comparison. Furthermore, experimentally we are currently able to change the sample angle by $\sim 20^{\circ}$. This technique is very useful for observing molecular overlayers, however, it is less useful when probing phenomena such as PSE when molecular composition is altered to a much deeper degree in the bulk.

\section{REFERENCES}

(1) Fluch, U.; Paneta, V.; Primetzhofer, D.; Ott, S. Uniform Distribution of Post-Synthetic Linker Exchange in Metal-Organic Frameworks Revealed by Rutherford Backscattering Spectrometry. Chem. Commun. 2017, 53, 6516-6519.

(2) Rouquerol, J.; Llewellyn, P.; Rouquerol, F. Is the BET Equation Applicable to Microporous Adsorbents. Studies in Surface Science and Catalysis 2007, 160, 49-56.

(3) Gomez-Gualdron, D. A.; Moghadam, P. Z.; Hupp, J. T.; Farha, O. K.; Snurr, R. Q. Application of Consistency Criteria To Calculate BET Areas of Micro- And Mesoporous Metal-Organic Frameworks. $J$. Am. Chem. Soc. 2016, 138, 215-224.

(4) Heinke, L.; Gu, Z. G.; Woll, C. The Surface Barrier Phenomenon at the Loading of Metal-Organic Frameworks. Nat. Commun. 2014, 5, 4562.

(5) Tian, F. Y.; Cerro, A. M.; Mosier, A. M.; Wayment-Steele, H. K.; Shine, R. S.; Park, A.; Webster, E. R.; Johnson, L. E.; Johal, M. S.; Benz, L. Surface and Stability Characterization of a Nanoporous ZIF-8 Thin Film. J. Phys. Chem. C 2014, 118, 14449-14456.

(6) Chizallet, C.; Bats, N. External Surface of Zeolite Imidazolate Frameworks Viewed Ab Initio: Multifunctionality at the Organic-Inorganic Interface. J. Phys. Chem. Lett. 2010, 1, 349-353.

(7) Bennett, T. D.; Todorova, T. K.; Baxter, E. F.; Reid, D. G.; Gervais, C.; Bueken, B.; Van de Voorde, B.; De Vos, D.; Keen, D. A.; Mellot-Draznieks, C. Connecting Defects and Amorphization in UiO-66 and MIL-140 Metal-Organic Frameworks: a Combined Experimental and Computational Study. Phys. Chem. Chem. Phys. 2016, 18, 2192-2201.

(8) Uzarevic, K.; Wang, T. C.; Moon, S. Y.; Fidelli, A. M.; Hupp, J. T.; Farha, O. K.; Friscic, T. Mechanochemical and Solvent-Free Assembly of Zirconium-Based Metal-Organic Frameworks. Chem. Commun. 2016, 52, 2133-2136.

(9) Katsenis, A. D.; Puskaric, A.; Strukil, V.; Mottillo, C.; Julien, P. A.; Uzarevic, K.; Pham, M. H.; Do, T. O.; Kimber, S. A. J.; Lazic, P.; Magdysyuk, O.; Dinnebier, R. E.; Halasz, I.; Friscic, T. In Situ X-ray Diffraction Monitoring of a Mechanochemical Reaction Reveals a Unique Topology Metal-Organic Framework. Nat. Commun. 2015, 6, 1-8.

(10) Yan, J. J.; Carl, A. D.; Maag, A. R.; MacDonald, J. C.; Muller, P.; Grimm, R. L.; Burdette, S. C. Detection of Adsorbates on Emissive MOF Surfaces with X-ray Photoelectron Spectroscopy. Dalton Trans. 2019, 48, 4520-4529. 